\title{
DOE/ET-5109-1 \\ Development of an Electrical Load Demand and Response Model Based on a Rational Synthesis From Elementary Devices
}

July 1979

Contract No. EX-78-C-01-5109

Prepared for:

U.S. Department of Energy

Assistant Secretary for

Energy Technology

Division of Electric Energy Systems 


\section{DISCLAIMER}

This report was prepared as an account of work sponsored by an agency of the United States Government. Neither the United States Government nor any agency Thereof, nor any of their employees, makes any warranty, express or implied, or assumes any legal liability or responsibility for the accuracy, completeness, or usefulness of any information, apparatus, product, or process disclosed, or represents that its use would not infringe privately owned rights. Reference herein to any specific commercial product, process, or service by trade name, trademark, manufacturer, or otherwise does not necessarily constitute or imply its endorsement, recommendation, or favoring by the United States Government or any agency thereof. The views and opinions of authors expressed herein do not necessarily state or reflect those of the United States Government or any agency thereof. 


\section{DISCLAIMER}

Portions of this document may be illegible in electronic image products. Images are produced from the best available original document. 
Available from:

Nationa1 Techniral Information Service (NTIS)

U.S. Department of Commerce

5285 Yort Royal Rodd

Springfield, Virginia 22161

Price: Printed Copy: $\$ 6.00$

Microfiche: $\$ 3.00$ 


\section{Development of an Electrical Load Demand and Response Model Based on a Rational Synthesis From Elementary Devices}

July 1979

Prepared by:

Georgia Institute of 'Technology

Atlanta, Georgia

Contract No. EX-78-C-01-5109

Prepared for:

U.S. Department of Energy

Assistant Secretary for

Energy Technology

Division of Electric Energy Systems

Washington, D.C. 20585

This report was prepared as an account of work sponsored by the United States Govemment. Neither the United States nor the United States Department of Enited States nor the United Stanes, nor any of their Energy, nor any of their employees, nor any of their

contractors, subcontractors, of their employees, makes

any warranty, express or implied, or assumes any legal

liability or responsibility for the accurecy, completeness

or usefulness of any information, apparatus, product or

process disclosed, or represents that its use woulo hot

infringe privately owned rights. 


\section{NOTICE}

This report was prepared as an account of work sponsored by the Ilnited States rinuernment Neither the IInitert States nnr the IIniterl States Department of Energy, nor any of their employees, makes any warranty, express or implied, or assumes any legal liability or responsibility for the accuracy, completeness, or usefulness of any information, apparatus, product, or process disclosed, or represents that its use would not infringe privately owned rights. Reference herein to any specific commercial product, process, or service by trade name, mark, manufacturer, or otherwise; does not necessarily constitute or imply its endorsement, recommendation, or favoring by the United States Government or any agency thereof. The-views and opinions of authors expressed herein do not necessarily state or reflect those of the United States Government or any agency thereof. 


\section{Faculty Participants}

Dr. A. S. Debs

Dr. C. Y. Chong

Dr. M. R. Corley

\section{Student Participants}

K. Bhipal

R. Malhami

J. Murad

H. Sotoodeh

Georgia-Institute of Technology

Atlanta, Georgia 
TABLE OF CONTENTS

List of Figures

List of Tables.

I. PROJECT OVERVIEW

1.1 Objectives and Scope

1.2 Load Model Characteristics

1.3 Selection of Model Hierarchies

1.4 Demand Factors of Influence.

1.5 Synthesis Methodology.

1.6 Validation and Model Truning.

II. FUINCIIUNAL/ELECT́TICAL DECOMPOSITION OF LOAD MODELS. . . . . . . .

2.1 Introduction .......................

2.2 Structure of Individual Component Load Models. . . . . .

2.3 Functional Models. . . . . . . . . . . . . . . .

2.4 Electrical Device Models . . . . . . . . . . . .

III. FUNCTIONAL MODELS .......................

3.1 Introduction ......................

3.2 Service Demand and Functional State. . . . . . . . . . . .

3.3 Memoryless Functional Model.

3.4 Weakly Driven Functional Múdel

3.5 Strongly Driven Functional Model

3.6 Stochastic Hybrid State Functional Models. . . . . . . .

3.7 Special Cases. . . . . . . . . . . . . . .

IV. AGGREGATION OF FIINCTTONAL MODELS. . . . . . . . . . . . . . . .

4.1 Introduction . . . . . . . . . . . . . . .

4.2 Assumptions of the Aggregation Modcl. . . . . . . . . .

4.3 Aggregation of the General Functional Mudel. . . . . . .

4.4 Special Cases. . . . . . . . . . . . . . . . . . . 
V. ELECTRICAL DEVICE RESPONSE MODELS. . . . . . . . . . . . . . 53

5.1 Introduction. . . . . . . . . . . . . . . . . . 53

5.2 Aggregation of Electrical Devices (Steady-State). . . . . 54

5.3 Examples of Component Response Models . . . . . . . . . . 58.

5.4 Induction Motor Load Models . . . . . . . . . . . . . 61 APPENDIX A: Functional Model for Electric Water Heater. . . . . . . 71 APPENDIX B: Functional/Electrical Models of Buildings . . . . . . 73

B.1 Introduction. . . . . . . . . . . . . . 73

B.2 Structure of a Building Load Mode1. . . . . . . . . . . 74

B. 3 Mathematical Model' Description. . . . . . . . . . . . 74 REFERENCES . . . . . . . . . . . . . . . ..... . 78 
1.1 Hierarchies Associated with Load Model . . . . . . . . . . . 4

1.2 Relationship Between the Modeling Steps: . . . . . . . . . . 8

2.1 Input-Output Form of Component Load Model. . . . . . . . . . . 11

2.2 Decomposition of Component Load Model. . . . . . . . . . . 15

2.3 Functional Model . . . . . . . . . . . . . . 18

2.4 Electrical Device Model. . . . . . . . . . . . . . 18

3.1 Relationship Between Service Demand and Electrical Demand. . . . 22

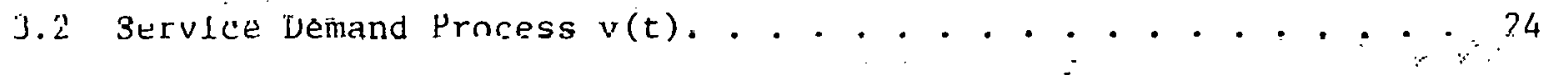

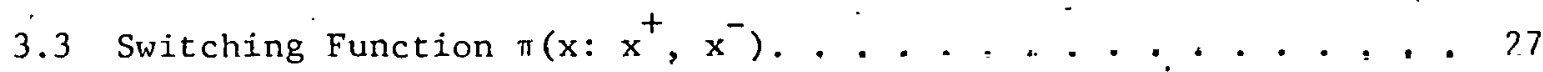

3.4 Interconnection of Continuous and Discrete State Subsystens. • . 27

3.5 Evolution of $x(t)$ and $m(t)$. . . . . . . . . . . . 28

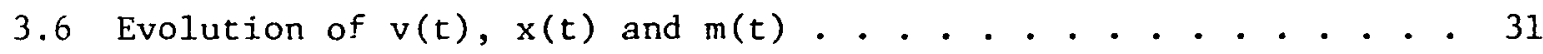

3.7 Relationship Between $x(t), \Lambda_{10}(t), \Lambda_{01}(t)$ and $m(t) . . . . . .35$

4.1 Decomposition of Aggregated Load Model . . . . . . . . . . 41

4.2 Aggregation of Functional Models . . . . . . . . . . . . 43

4.3 The Marked Point Process and its Mark Accumulation Prosess $m_{k}(t) \quad 45$

4.4 Superposition of Multivariate Point Processes. . . . . . . . . 47

4.5 Superposition of $\mathrm{m}_{\mathrm{k}}(\mathrm{t})$. . . . . . . . . . . . . . 51

b.1 Simplified Induction Motor Equivalent Circuit. . . . . . . . . . 63

5.2 Simplified Equivalent Circuit Representing Two Motors in Parallel (a) original circuit (b) reduced circuit. . . . . . . 63

53. Structure of a Building Load Simulation Mude1. . . . . . . . 7b 


\section{LIST OF TABLES}

Page

2.1 Residential Components as Energy Converters . . . . . . . 13 
1.1 Objectives and Scope

The objective of this project is to develop and test a viable methodology which can be used to synthesize models of power system load to aid in the following major functions:

- On-line automatic generation control

- Short-term bus load forecasting

- Stochastic power-flow analysis

- Load management

- Operational planning

- Security assessment

- Power system stability analysis

The scope of the project is limited to the development of methodology with all associated simulation programs. In order to avoid functioning in a vacuum, a limited amount of information obtainable from utilitics ana government agencies will be utilized in providing a credible data base for the validation methodology and the tuning of model parameters. Althougn the developed models will be primarily useful in the system operation context, the potential planning uses will be properly delineated.

\subsection{Load Model Characteristics}

The primary considerations in load model developments are:

(a) Ability of a utility to build the required data base on a rational basis which capitalizes strongly on information already available in the utility, state and government agencies data 
files with minimal amounts of additional information.

(b) Ability to validate and tune model parameters from limited tests on representative statistical samples.

(c) Ability to incorporate the developed models in the application areas quoted above.

The aim of the methodology is to develop two types of load models. The first type is a load-demand model which has the following characteristics:

- It provides an accurate short-term forecast of bus loads over the range of minutes to hours and days based on weather and historical use pateria lata.

It provides an estimate of the make-up of each bus load in terms of primary electrical components with associated statistics.

-It predicts the changes in time in demand patterns due to the implementation of specific load-management procedures.

The second type is " a load-response model which utilizes the information from the load-demand model to obtain low-order dynamir (in rerms of differential equations, or transfer functions) models which can be used in un-line control like aucomatic generation control (AGC), in the detection of emergencies, transient stability analysis, and others.

In response to these aims and considerations, the methodology is constructed in accordance with the following:

-Selection of model hierarchies

-Identification of demand factors of influence

-Synthesis methodology

-Validation and mocicl tuning methodology

These topics are now briefly discussed in the sequel. 
$1.3^{*}$ 'Selection of Model Hierarchies

In Figure 1.1 we illustrate load model hierarchies starting from the system level, down to substation, building and finally electrical device level. We foresee a modeling function at each level depending on the demand factors of influence and the required applications.

1.4 Demand Factors of Influence

Since only short-term effects are contemplated for this project, long-term economic and technological factors of influence are only considered implicitly. The explicit factors considered are:

-Weather

-Human use patterns

-Special events

Weather has a direct but complex impact on building spaceconditioning devices: Hence, there is a need for building thermal/electrical weather sensitive models. Human use patterns can be regular (lighting, hot water usage) with predictable statistics, or abnormal (strikes, sports events,'etc.). Special events like abnormally cold or hot weather will create conditions like urging customers to raise or lower thermostats, or cause utility to drop voltage by a given percentage. Load management can be treated in this light also.

1.5 Synthesis Methodology

The synthesis methodology consists of three basic steps:
(a) Electrical device modeling
(b) Functional load modeling
(c) Aggregation 


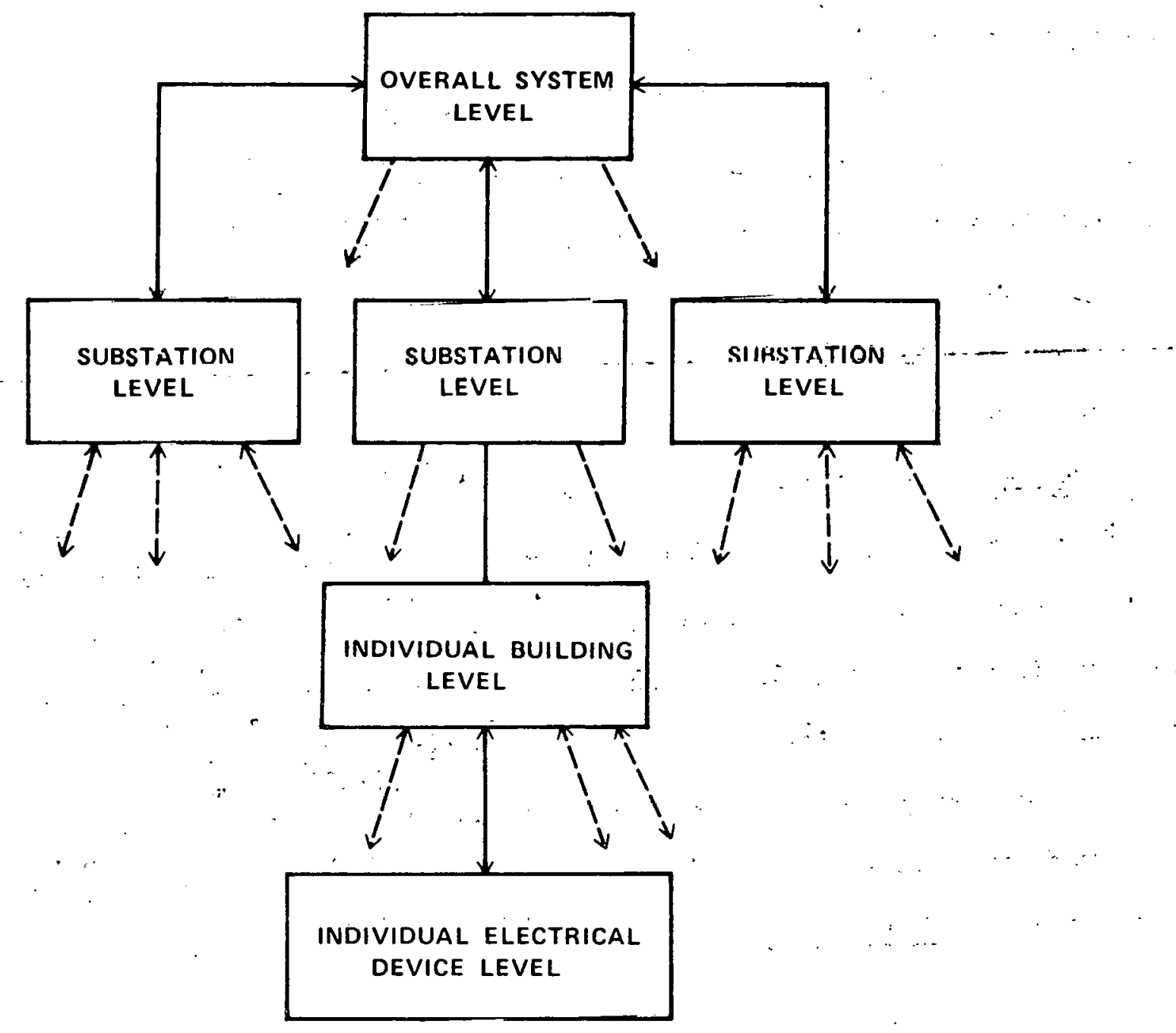

Figure 1.1 Hierarchies Associated with Load Model 
Electrical devices will be classified according to function as

\section{follows :}

1. Space conditioning

Air conditioners

Heat pumps

Resistive heating

2. Hot water heaters

3. Incandescent lights:

4. Fluorescent lights

5. Refrigerators

6. Televisions

7. Appliances

8. Industrial and special loads

For each device we obtain both the steady-state characteristics as well as the dynamic characteristics (if warranted). Essentially, the real and reactive demand of a device, under steady-state conditions are given by:

$$
\begin{aligned}
\text { real demand } & =P \\
& =P(V, f) \\
\text { reactive demand } & =Q \\
& =Q(V, f)
\end{aligned}
$$

where $V, f$ are voltage and frequency, respectively.

Under dynamic (e.g., transient) conditions, a state vector $x$ is associated with the device, and a vector differential equation describes system dynamics

$$
\frac{d x}{d t}=f(x, v, f)
$$


The output, as a consequence, is given by

$$
\begin{aligned}
& P=P(x, V, f) \\
& Q=Q(x, V, f)
\end{aligned}
$$

Functional load modeling consists of establishing models whose inputs are the stochastic demand influence factors and whose outputs are the stochastic processes of on-off behavior of associated electrical devices.

The last step is that of aggregating many devices into a general model. Inputs to this model will consist of:

-representative random processes of use patterns for each type of user

-statistics on device ratings, sot pointo, and otlies parameters

-meteorological statislics

Outputs of the aggregated model will consist of

-total electrical demand

-statistics of electrical demand

-number and type of units that are "ON" and the uncertainty associated with that number

We propose here to investigate two approaches. The first approach is analytical with the functional model of individual devices as the starting point. In the second approach, model structure is assumed, and its parameters are computed from representative simulätions by means of modern estimation techniques that are applicable to both linear and non-linear processcs.

Finally, we look at aygregaring transient models given the number and type of devices in the on mode. For example, induction motor loads may be lumped into equivalent machines for transient analysis. Again, the analytical and model idelltification approaches will be investigated. In 
either case, enough simulations will be performed to identify the uncertainties in the aggregated models. The relationships between the three modeling steps is illustrated in Figure 1.2 using water heaters as an example.

\subsection{Validation and Model Tuning}

In the validation and model turing methodology, we employ a procedure for each level in the hierarchy. At the device level; laboratory, limited field, and simulation testing will be needed. Identification of specific use patterns will require methodologies for the selection of adequate statistical samples for field testing. Thermal response of buildings can be tested in the simulation model against a detailed simulator and in realIife through the selection of adequate statistical samples for field tests. Tuning at the substation level can be achieved against a substation load forecasting procedure using regression or parameter estimation techniques. And, finally, at the system level, the system load forecast, based on available techniques, is utilized to tune the synthesized model and vice-versa. 


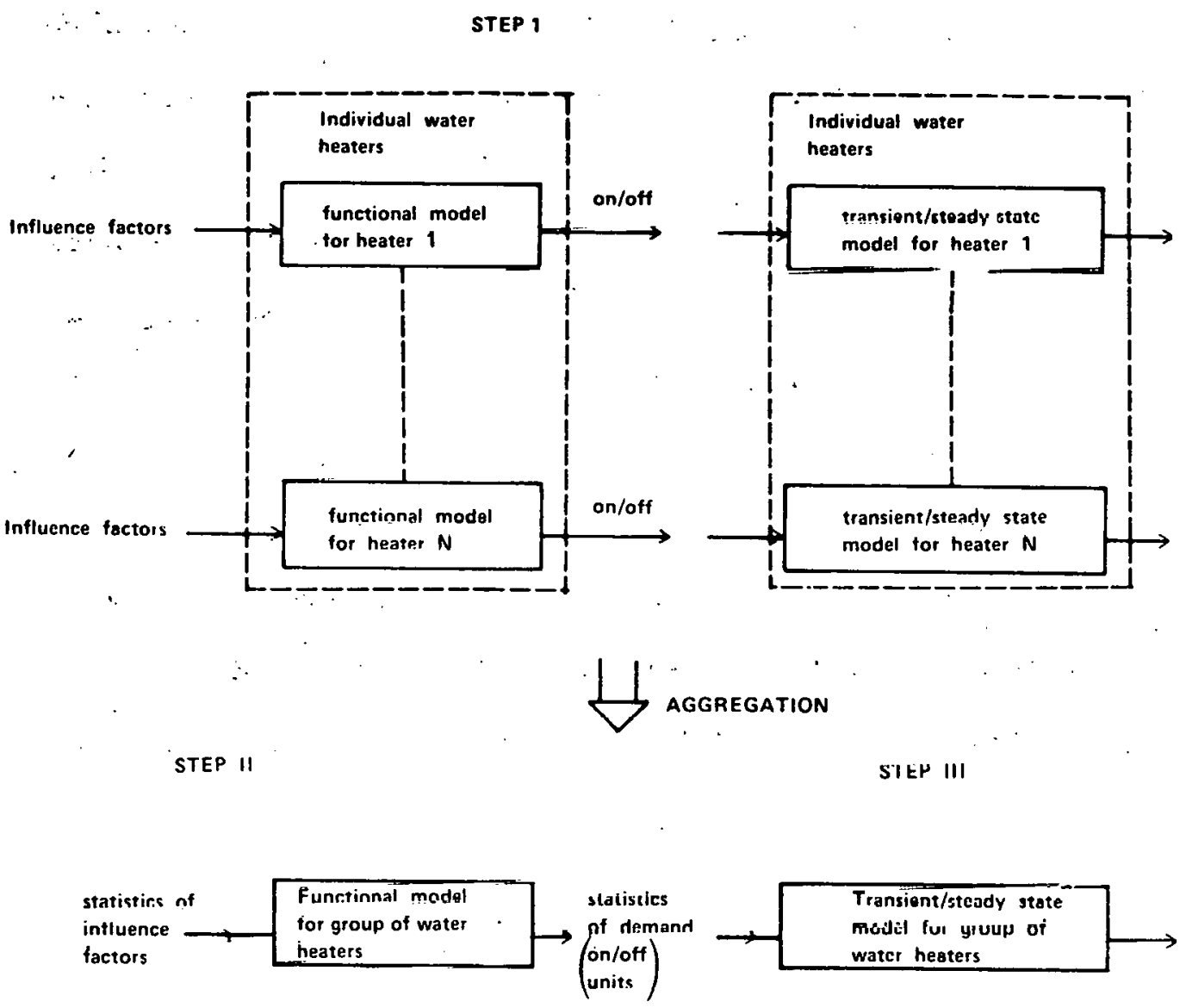

Fịgure 1.2 Relaṭinnthip Botwiosen llie Mudeilng Steps 
II. FUNCTIONAL/ELECTRICAL DECOMPOSITION

OF LOAD MODELS

\subsection{Introduction}

As outlined in the previous chapter, the physically based lnad aggregation scheme depends on a hierarchy of load models. At the lowest level of the hierarchy are the individual components or devices which constitute all the primitive loads in the system. These include individual air conditioners, space heaters, water heaters, refrigerators, lights, washers and dryers, etc., in the residential sector, and various industrial loads such as synchronous and induction motors, or arc furnaces, in the industrial sector. A similar list can be found for the commercial sector. The power demand of each of these components is affected by a variety of inputs such as human use patterns, the weather, voltage and frequency. The dependence is in general dynamic in nature since the present load may depend on the present and past history of the influence factors. The load model of a component is thus usually a dynamic system which can be nonlinear in nature. Nonlinear dynamic systeins are difficult to analyze. The aggregation of such nonlinear models is even more difficult. Careful examination of the process by which the influence factors affect the load indicates the load model consists of the interconnection of two dynamic systems: a functional model which relates the demand for the service of the component to the functional stace of the device and the electrical model which summarizes the effect on the load demand due to changes in the voltage or the frequency. 
In the following sections, we shall elaborate on the decomposition of the load mode1. This decomposition allows us to establish the connection between load demand and load response at the component level. Once aggregated, the same questions can be answered at the system level.

\subsection{Structure of Individual Component Load Mode1s}

For any individual component, the load (real and reactive power) depends on the time (time of the day, day of the week, etc.), the weather, human use patterns, voltage, and frequency of the electric supply. The dependence is generally dynamic in naturc, so that a component load model is a lynamic oystem with the tollowing inputs alud oucputs:

Inputs

weather

human use patterns

voltage

Erequency

Outputs

real power

reactive power

Note that human use patterns may be a function of the weather which is usually dependent on time. The relationship between the inputs and the oulputs depends on the function of the component, its mechaniral 28 well as its electrical construction. Thus, Figure ?.l can bc used tu represcnt the component load model in its most general form.

The inpute can be divided into two types:

a. Service demand-generating inputs. These are inputs which generate a demand for the service of the component. Thcy depend on the time of the day, the weather and the human use pattern. 


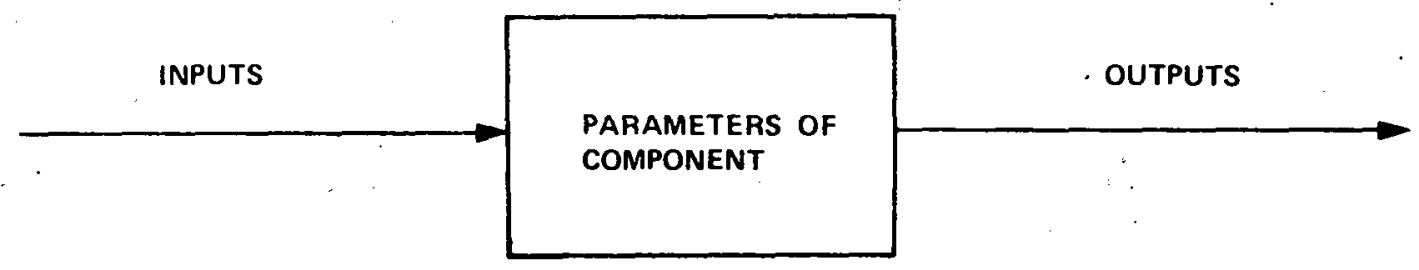

Figure 2.1 Input-Output Form of Component Load Model 
The service demand is the net input into the component load model and is usually independent of the voltage and frequency. It may be modified by actions such as time-of-the-day pricing and other incentives.

b. System inputs. Inputs such as voltage and frequency originate from the supply end of the power system. They are independent of individual service demands, but are determined at the system level by the total load connected, the configuration of the network, and the state of the generating system.

These two typcs of inpuls inceract to determine the load of the rnmponent in the folluwilug uanner. Une may regard each component ao an energy conversion device converting electrical energy iulu nther rypes ot energy on demand. This demand is the service demand and depends on certain inputs as discussed abovc. The energy needed is provided by the energy converter and its supply depends on the system inputs. In many components, the physical construction of the component allows for some storage of the energy demanded. Thus, a demand for the service of component may not result immediately in a demand for electricity. Rather, a control mechanism determines the operating state of the energy convercer, whether it should be on or of $\bar{f}$, or somewhere in between, based on the energy storage and possibly the demand for service. Table 2.1 lists several residential components, the types of energy demanded and whether storage ic posaible,

The partition of the inputs into two typeo affectiug differenc parts of the component suggests the decomposition of the load mudel inco a functional mudel and an electrical device model. The functional model has as its external input the service demand of the component and generates the operating state of the energy converter as its output. Physically, it 
Table 2.1 Residential components as energy converters

\begin{tabular}{|l|l|c|}
\hline \multicolumn{1}{|c|}{ Component } & Type of energy demanded & Possibility of energy storage \\
\hline Incandescent lights & $\begin{array}{l}\text { Thermal radiation in the } \\
\text { visible range } \\
\text { Hi-Fi equipment } \\
\text { Mechanical energy in the } \\
\text { audio range }\end{array}$ & No \\
$\begin{array}{l}\text { Electric oven } \\
\text { Electric water } \\
\text { heater }\end{array}$ & $\begin{array}{l}\text { Thermal energy } \\
\text { Electric space } \\
\text { heater }\end{array}$ & Thermal energy \\
Washer & Mechanical energy & Yes \\
\hline
\end{tabular}


includes the energy storage portion of the component and the control mechanism. The electrical device model has as its external inputs the voltage and frequency of the supply and generates the power demand as the output. Physically it includes the energy converter. This decomposition is illustrated in Figure 2.2.

There is interaction between the two subsystems in the load model. The functional (operating) state of the functional model evolves according to the power supplied by the energy converter as well as the power withdrawal due to the service demand. The operation of the electrical model depends, of course, on the functional state.

We now state the abovc decumpusition mathematically. Let

$t$ be the time indox

$v(t)$ be the service demand at time $t$

$u(t)$ be the vector of system inputs, namely, voltage and frequency

$y(t)$ be the power demand at time $t$.

Then the input-output form of the component load model is

$$
y(t)=F(t, v(\tau), u(\tau), \tau \leq t)
$$

where $F$ depends on the component under consideration. Note that $y(t)$ depend's on the past histories of the inputs in general. Also $v(t)$ will be a function of the weather $w(t)$ and the human use pattern $z(t)$, i.e.,

$$
v(t)=v(t, w(t), z(t))
$$

A dynamic rclationship may also hold here.

The deconposition of the load model implies that (2.2.1) can be replaced by the following three equations.

$$
y(t)=F_{e}(t, u(\tau), m(\tau), \tau \leq t)
$$




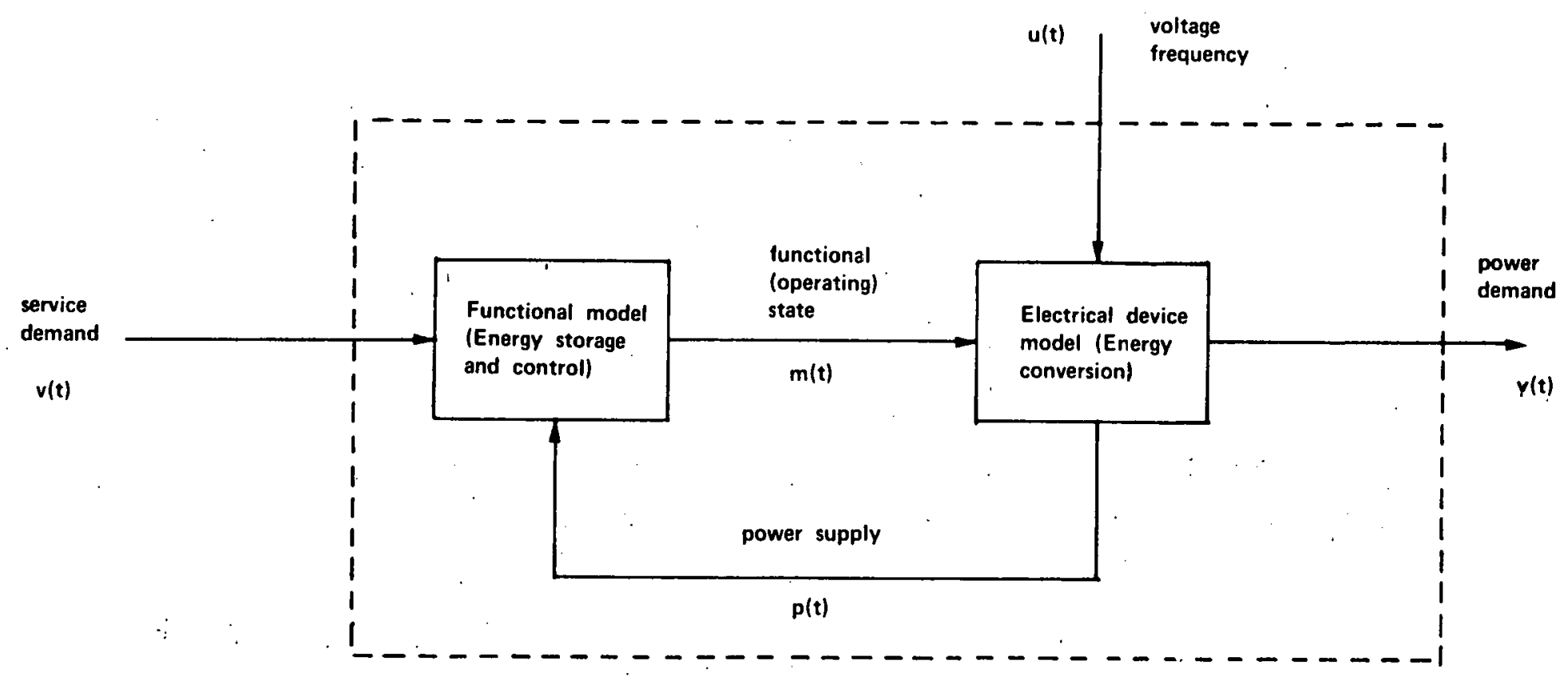

Load model

Figure 2.2 Decomposition of Component Load Model 


$$
p(t)=G(y(t))
$$

and

$$
m(t)=F_{f}(t, v(\tau), p(\tau), \tau \leq t)
$$

where $m(t)$ is the functional state of the system and $p(t)$ is the power supplied. $F_{e}$ describes the electrical device model and $F_{f}$ describes the functional model. Note that as $\mathrm{far}$ as $\overrightarrow{\mathrm{F}}_{\mathrm{e}}$ is concerned, $\mathrm{m}(t)$ is an external input. Similarly, $p(t)$ is the external input to the functional model.

Both the functional and the electrical device models may he nonlincar. In fart, in many caoco, the fullcliunal scace mit') is discrete in nature, representating a finite number of operating conditions for the electrical device model. The overall system is then a non-linear system with hybrid states ( 1 ) where both continuous and discrete variables are present in the system mode1. Such systems behave in ways which have a big impact on load management schemes.

\subsection{Functional Models}

In this section we make some qualitative observations on the functional model described by

$$
m(t)=F_{f}(t, v(\tau), p(\tau), \tau \leq t)
$$

A detailed discussion $n f$ the functional model will appear in the next rhapter.

The functional modcl relates lhe operating state of the energy converter in the component to the supply of power $p(t)$ and to the environmental factors and human use patterns through the service demand $v(t)$. $v(t)$ is the demand for power and will be in the form of light for 
'incandescent and fluorescent lights and thermal power for electric water heaters, etc. It is a function of time, weather and human use patterns. $p(t)$ represents the supply of power from the energy converter or the electrical device model. This term is present in many components and summarizes the effect of the system inputs $u(t)$ on the functional state. In a water heater, for instance, a drop in the thermal power supplied by the energy converter due to a drop in the voltage will result in a longer time for the water to heat up to the temperature of the thermostat setting. The functional state will thus evolve at a different rate.

The functional state $\mathrm{m}(\mathrm{t})$ may take on continuous values, as in the case of an incandescent light with a dimmer, or only discrete values as in a water heater. For discrete $\mathrm{m}(t)$, there may be two (Boolean or on-off) states as in the single element water heater or multiple states as in the dual element water heater. Though we formulate the equations for a general $\mathrm{m}(t)$, our attention is mostly restricted to the Boolean case.

When no energy storage is possible, as in the case of lighting equipment, the functional model becomes a static or memoryless system; otherwise it will be dynamic. The functional model is highly dependent on the intended use of the device and the interaction with the environment. Two devices which have the same electrical construction may have radically different functional models if they serve different purposes. The functional model is important since it can be used to characterize changes in the operating state of the device due to weather and human use patterns, assuming a given rate of power supply from the electrical device model. At the component level, it defines the lood demand.

\subsection{Electrical Device Model}

The electrical device model relates the electrical power demand of 


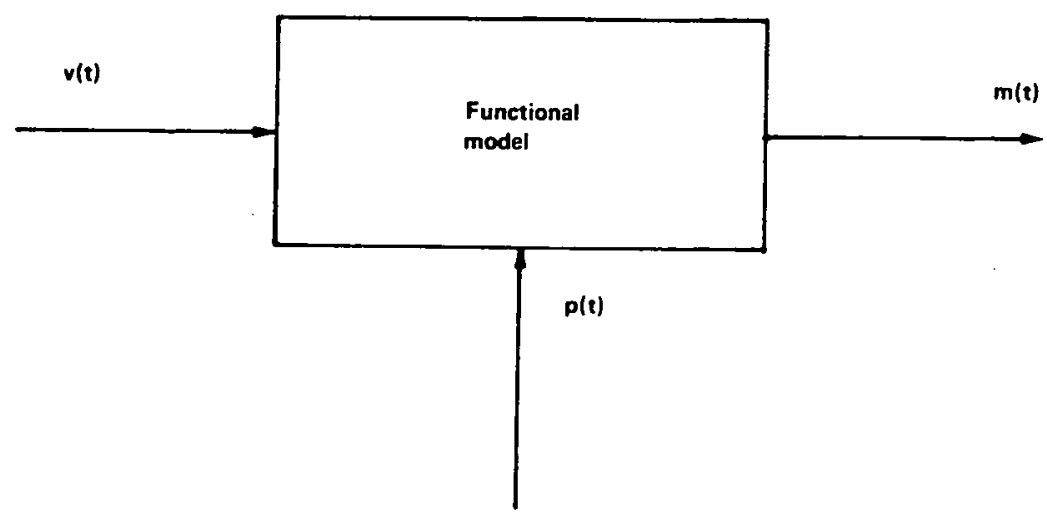

Figure $2.3 \quad$ Functional model

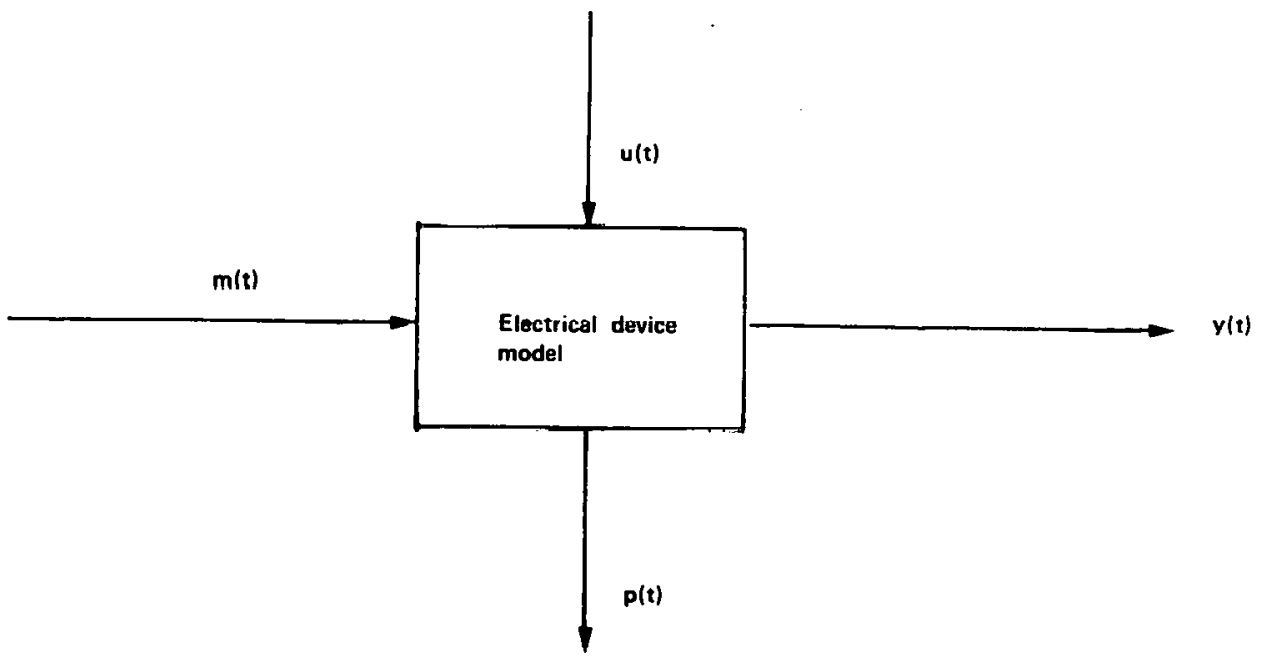

Figure 2.4 Electrical Device Model

$-18-$ 
the device to the supply voltage and frequency given the operating state of the electrical portion.

$$
y(t)=F_{e}(t, u(\tau), m(\tau), \tau \leq t)
$$

$m(t)$, the operating state or functional state, may be Boolean, indicating whether the electrical device or energy converter is on or off. Or it may take on a continuous range of values as in the mechanical load a motor is called on to deliver. $u(t)$, the system voltage and frequency, is an external input. $y(t)$ is the electrical power demand on the supply system. $p(t)$, the power supplied by the energy converter depends on the inputs $m(t)$ and $u(t)$ and affects the functional model.

Two components having identical functional models may have different electrical models if the constructions of the energy converters are different. Under these circumstances, the responses of the two components to the same change in voltage or frequency will be different. For example, incandescent and fluorescent lights behave differently when there is a dip in the line voltage. When there is a feedback from the electrical model to the functional model, the functional states will then also behave differently.

Strictly speaking, the initial states of the electrical device models are also quite important. In many components, however, the dynamics of the electrical models is much faster than that of the functional model so that for all practical purposes, one may deal with a steady state electrical device model. 


\subsection{Introduction}

The functional model is a very important part of the overall component load model. It characterizes the evolution of the load due to environmental and human use factors. In the absence of voltage and frequency changes, the functional model determines the dynamic behavior of the load demand. It is essential for components with energy storage and causes the service demand and the electrical power demand to be substantially different. As a result, a good understanding of the functional model is essential if one wants to understand, prodict and mallage lle electrical power load.

Lictle has been done on the functional modeling of component loads. Our discussion in this chapter will start with a presentation of three representative classes of functional models, classified according to the presence or absence of energy storage and the nature of the driving processes. These three classes are not exhaustive but represent the bulk of romponent loads in the rosidentid sectur. This will be followed by a general formulation of the functional model in terms nf stochastic hybrid state systems. The sturdy of such systems is still at an elementary stage. As a result, we can only provide partial characterizations to some of the mode1s.

\subsection{Service Demand and Functinnal state}

Given the power $p(t)$ sipplied by the clectrical device model, the functional model relates $\mathrm{m}(\mathrm{t})$, the operating state of the electrical 
device model to $v(t)$, the service demand for the component. One cannot over-emphasize the point that the operating state of the component may not be the same as the service demand. Take two water heaters with the same construction as an example. Identical demands for hot water may cause one water heater to turn on but not the other, depending on the initial temperature of the water. This is true whenever energy storage is possible in the component. Thus, $m(t)$ should not be assumed a prior but should be computed given $v(t)$ and $p(t)$.

The external input into the functional model is assumed to be $v(t)$, the service demand or the demand for power in its converted form. of course, $v(t)$ is a function of $z(t)$, the human use pattern and $w(t)$, the weather. However, to highlight the fact that the component device has a sole function of supplying power, we shall use $v(t)$ as the input to the functional model.

Our main objective is to characterize $\mathrm{m}(t)$ for a single component and ultimately the sum of $m(t)$ 's for a lot of components. It is necessary to make the appropriate assumptions on $v(t) . v(t)$ is assumed to be a stochastic process since it is never known exactly for a given component, especially at the system level. The statistics of $v(t)$ depends on $w(t)$ and $z(t)$ and varies from component to component. A complete model of the functional state would also include the service model. This will not be considered in our study. In what follows, we assume $v(t)$ to be a given stochastic process and try to characterize $m(t)$ : of course, $v(t)$ can have all the necessary variations present in a real life situation, such as dependence on time of the day, etc.

\subsection{Memoryless Functional Model}

In this and the following two sections, we shall consider three 


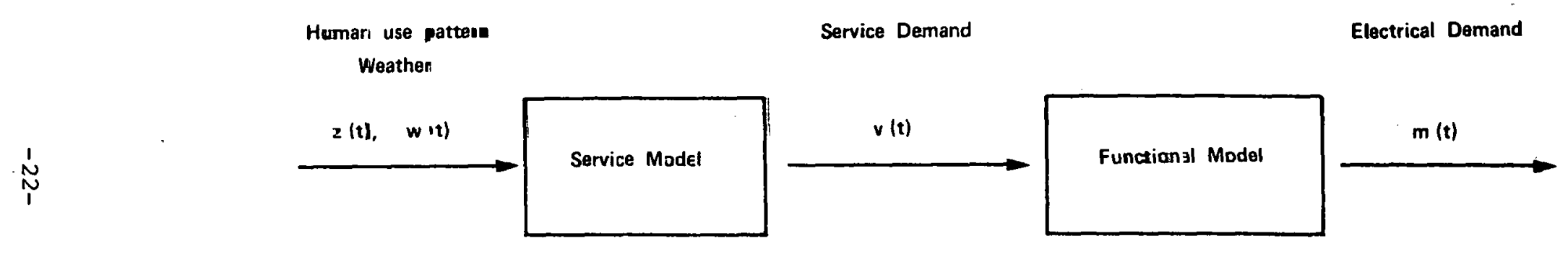

Figure 3.1 Relationship Between Service Demand and Electrical Demand 
typical classes of functional models. This will be used to motivate the general stochastic model introduced later on.

In many devices, such as incandescent and fluorescent lights, television sets, etc., there is no energy storage in the system. The functional model becomes a memoryless or static system and $m(t)$, the functional state of the component depends on the instantaneous value of $v(t)$, the demand for service of the device.

$$
m(t)=F_{f}(t, v(t))
$$

If $v(t)$ has only two states such as in a fluorescent light with on and off being the two states, it can be represented by means of an alternating renewal process $^{(2)}$. The durations over which the demand is on is modeled as a sequence of independent random variables $t_{1}, t_{2}, \ldots .$. Similarly the durations over which the device is off is modeled as another sequence of independent random variables $\tau_{1}, \tau_{2}, .$. . An interval $t_{i}$ is followed by an interval $\tau_{i}$, then by $t_{i+1}$ and so on. This is illustreated in Figure 3.2. $m(t)$ will exhibit the same type of on-off behavior. The probability distributions of the random variables $t_{i}$ and $\tau_{i}$ may depend on time as well as another process 'such as the weather. If the probability densities of $t_{i}$ and $\tau_{i}$ are exponential, then $v(t)$ is a Markov jump process with two states.

In a general case, the magnitude of the demand $v(t)$ may also be random but constant over each on period. We then have a general jump process. The functional state will also be a general jump process. This is the situation where the load is variable, as in an incandescent light with a dimmer. 


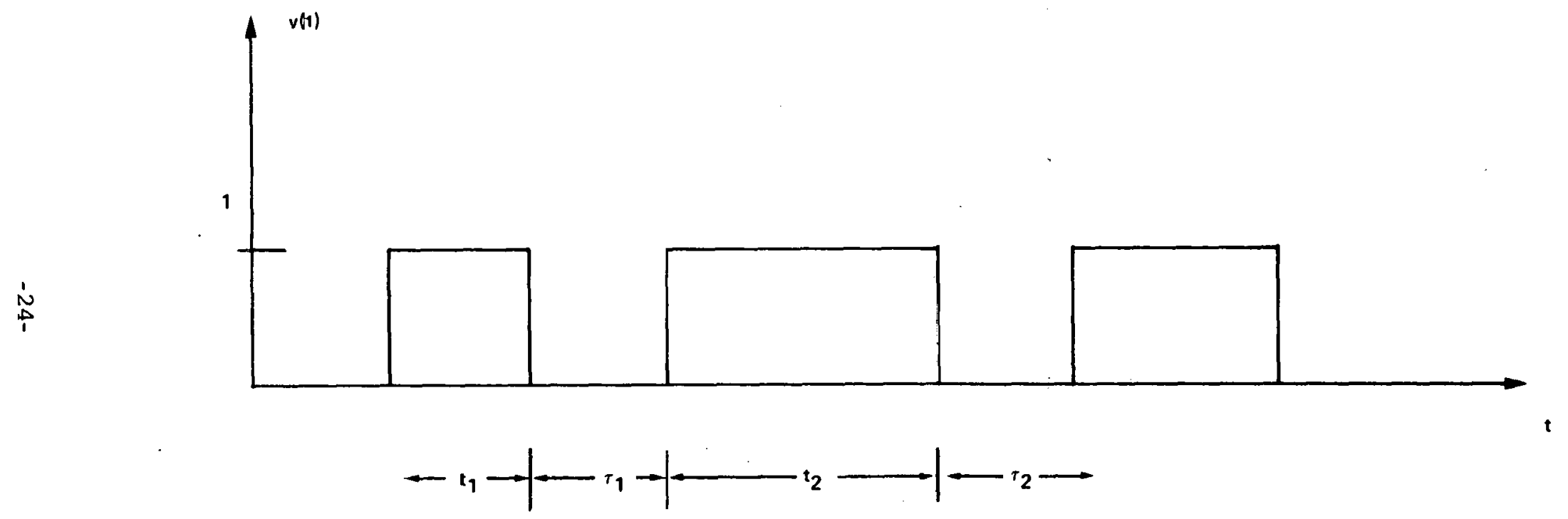

Figure 3.2 Service Demand Prócess vit) 


\section{4' Weakly Driven Functional Mode1}

In some devices, the electrical energy is : onverted into other forms of energy which can be stored. Furthermore, the external factors which influence the energy storage behave like random noises with fairly flat spectral densities. An example may be found in the cooling or heating system of a building. In a residential building, heating and/or air conditioning account for a major part of the electrical load. The load model of such systems has been considered in (3). The electrical part of the device turns on or off when the temperature reaches certain fixed values. To be specific, we shall consider an electric heating system with a resistive heater activated by a thermostat. Heat is lost from the building through the walls, the floor and the roof. In addition, heat is also lost when somebody enters and leaves the building and gained from human activity. This type of effect can be modeled as noise. Functional models for a building can be very complicated. As a start we shall consider a highly simplified linear model

$$
\dot{x}(t)=-a(x(t)-w(t))-v(t)+p(t) m(t)
$$

where

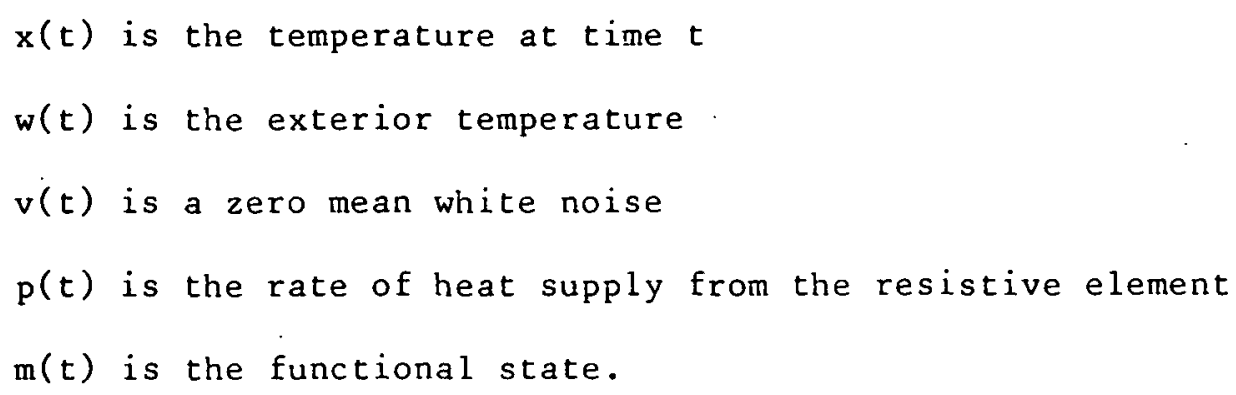

When the functional state $m(t)=1$, the heater is on and the temperature rises. Whell lie functional state $\mathrm{m}(t)=0$, the heater is off and the temperature $x(t)$ fallo.

The switching of $\mathrm{m}(t)$ depends on the thermostat settings. Let $\mathrm{x}^{+}$and $x^{-}$be the temperatures at which the heater is turned of $f$ and on. Then the 
switching of $\mathrm{m}(t)$, the functional state is as follows. For an arbitrarily. $\operatorname{small} \Delta t>0$

$$
m(t+\Delta t)=m(t)+\pi\left(x(t): x^{+}, x^{-}\right)
$$

with $\pi$ defined as

$$
\pi\left(x: x^{+}, x^{-}\right)= \begin{cases}0 & x^{-} \leq x^{+}<x^{+} \\ -1 & x^{+} \leq x \\ +1 & x<x^{-}\end{cases}
$$

Thus the functional model is composed of two interconnected subsystems: a linear system with a continuous atate $x(t)$ whuse evulution depends on $w(t)$ and a nonlinear system with discrete state $m(t)$ whose transition is triggered by $x(t)$.

The continuous state system is the energy storage component, and the discrete state system corresponds to the control mechanism. Suppose $m(t)=$ 1 between 0 and $t_{1}, x(t)$ evolves according to

$$
\dot{x}(t)=-a(x(t)-w(t))-v(t)+p(t)
$$

with initial condition $x(0)=x^{-}$.

$$
\begin{aligned}
& \text { Between } t_{1} \text { and } t_{1}+\tau_{1}, m(t)=0 \text { and } x(t) \text { is given by } \\
& \dot{x}(t)=-a(x(t)-w(t))-v(t)
\end{aligned}
$$

with initial condition $x\left(t_{1}\right)=x^{+}$.

The evolution of $x(L)$ and $n(t)$ is illustraced in figure $3 . b$. Notice that if the noise $v(t)$ is absent, then the switching of $m(t)$ between 0 and 1 is periodic. When noise is present, the cycling of $m(t)$ is no longer deterministic. This type of cycling is ubserved in electric heaters and 


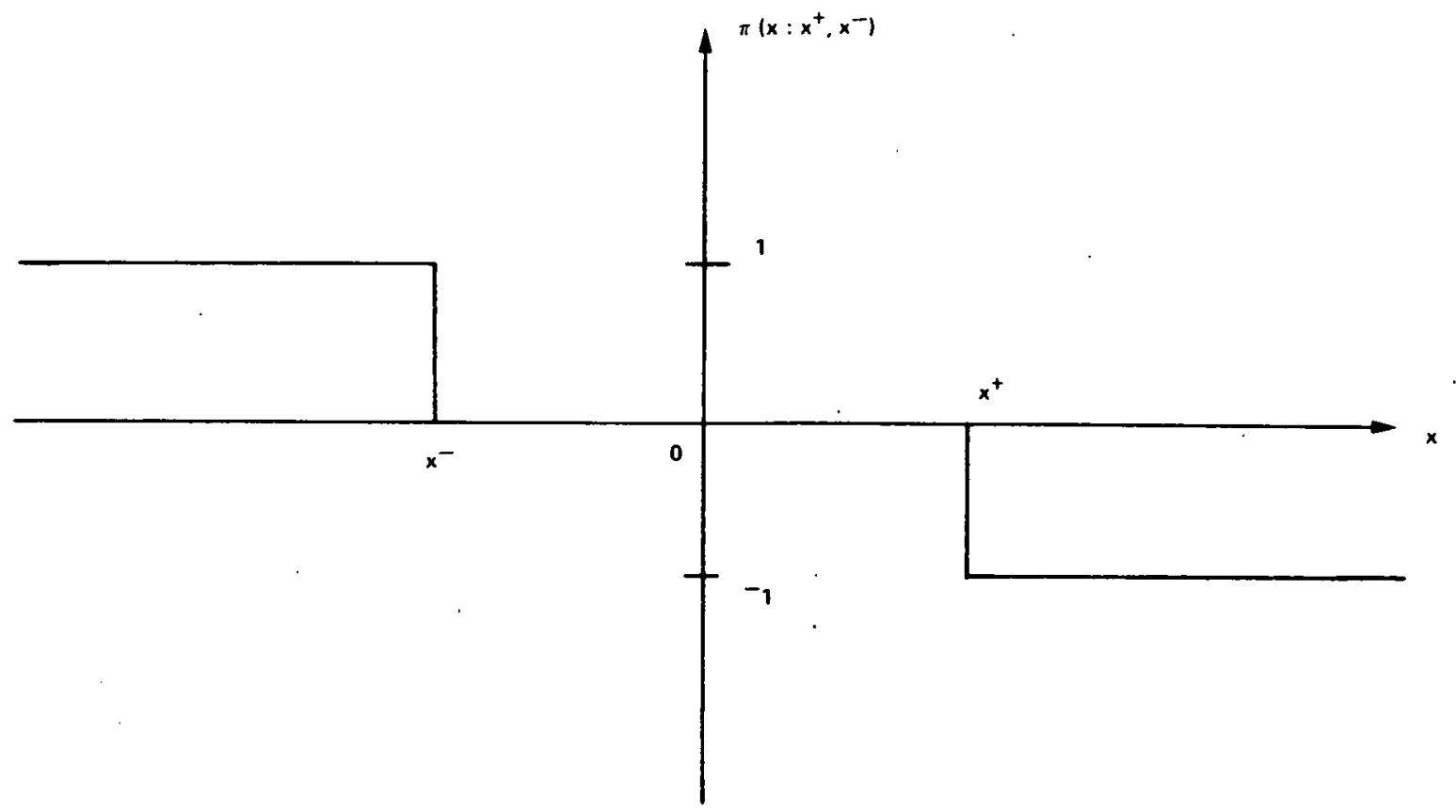

Figure 3.3 Swlehing Function $\pi\left(x: x^{+}, x^{-}\right)$

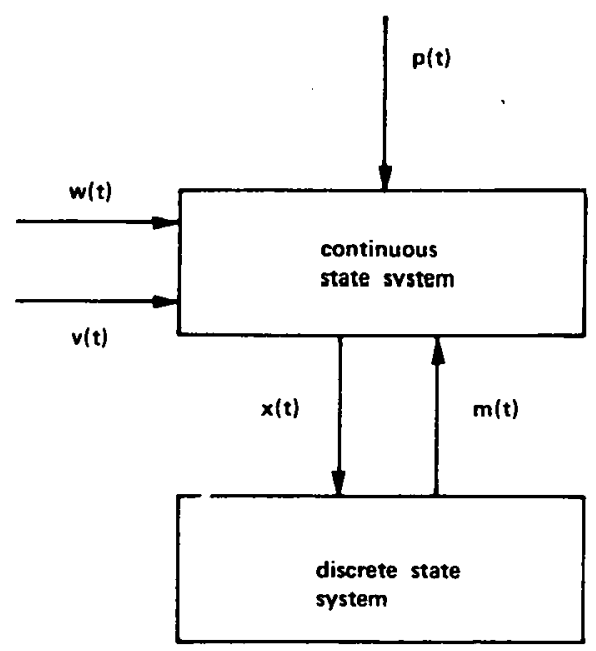

Figure 3.4 Interconnection of continuous and discrete states subsystems 


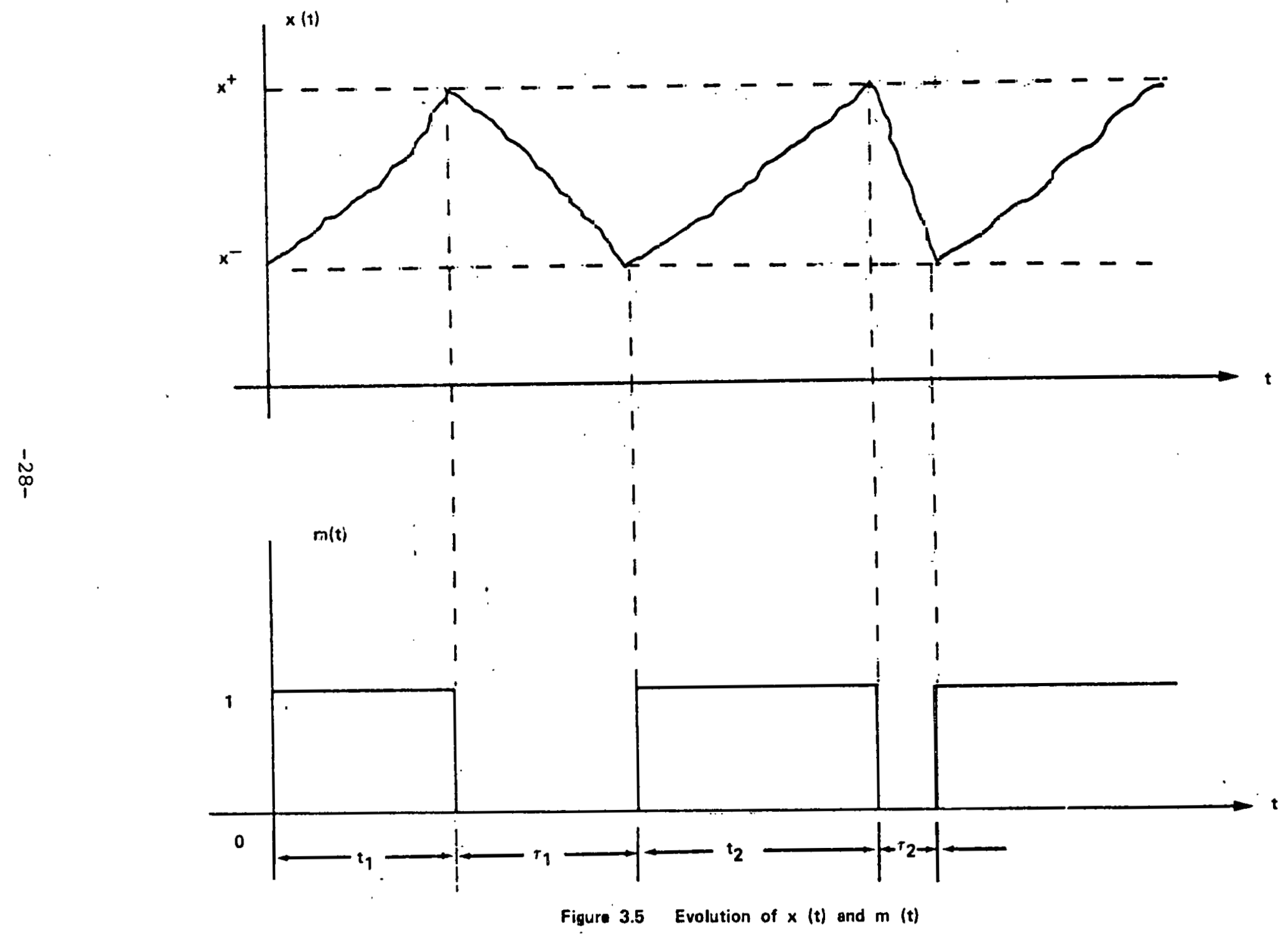


several other devices. As shall be seen later on when we study aggregation, the stochastic treatment of the cycling phenomenon is essential.

Systems with both continuous and discrete states are called hybrid state systems. They have been studied as differential equations with discontinuous right hand sides and variable structure systems ${ }^{(4-7)}$, . in discontinuous control ${ }^{(8,9)}$, as well as in optimization ${ }^{(1)}$. However, systematic study of such systems only began to draw more attention recently. In Section 3.6 we shall introduce a stochastic framework which includes this weakly driven functional mokel as well as the strongly driven functional model to be considered in the next section.

\subsection{Strongly Driven Functional Model}

The strongly driven functional model has the same structure as the weakly driven functional model of the previous section. $v(t)$, the service de mand; however, is now not a noise process. Rather, it is a conscious dem and by the consumer and can be modeled as a jump process, i.e., a random driving. input which is piecewise constant. An example of this type of functional model can be found in the electric water heater. A simple model of this, derived in A ppendix $\mathrm{A}$ is given by

$$
C \dot{x}(t)=-\alpha\left(x(t)-x_{a}(t)\right)-v(t)\left(x_{d}-x_{i}(t)\right)+p(t) m(t)
$$

where the symbols are as defined in Appendix A. For $x_{i}(t)$ constant the equation is of the form

$$
\dot{x}(t)=-a(x(t)-w(t))-b v(t)+p(t) m(t)
$$

This is similar to the weakly driven model considered in the previous section except that $v(t)$ is now piecewise constant with random switching 
times and random amplitudes. $\mathrm{m}(\mathrm{t})$ will switch between 0 and 1 according to i equation $(3.4 .2)$.

To understand this model better, we shall consider a special case where $a=0$, i.e., there is no loss in the system. Assume also that $\mathrm{x}^{+}=\mathrm{x}^{-}$ i.e., $m(t)=1$ or the heater will stay on as long as the temperature falls below $\mathrm{x}^{+}=\mathrm{x}^{-}$. Consider a sample function of $\mathrm{v}(\mathrm{t})$ as shown in Figure 3.6 where it switches on at $t=0$. At $t=0, v(t)$ switches from 0 to $A_{1}$ for $a$ duration of $s_{1}$. Over the interval $\left(0, s_{1}\right), x(t)$ evolves according to the equation (with $m(t)=1$ )

$$
\dot{x}(t)=-h_{1}+\dot{p}(t) \quad x(0)=x^{t}
$$

At $t=s_{1}, v(t)$ ewitches off and $x(t)$ evolves according to

$$
\dot{x}(t)=p(t)
$$

until $x(t)=x^{+}$at $t=t_{1}$. At that point $m(t)$ switches off and remains off until $v(t)$ is switched on again. Note that the duration $t_{1}, t_{2}$, etc., are proportional to $A_{1} s_{1}, A_{2} s_{2}$, etc., provided $p(t)$ remains constant and $m(t)$ switches off before the next demand in $v(t)$ arrives. Tn this simplified model it is possible to characterize $v(t)$ by the turn-on times together with the energy of the demand $\mathrm{A}_{1}{ }_{1}, \mathrm{~A}_{2}{ }_{2}$, elc. Note that in this strongly driven model, $\mathrm{m}(t)$ is no longer a cycling process but depends on the arrival of the service demands. Furthermore, although the functional state $m(t)$ may switch on at the same inscant as $v(t)$, it does not switch nff ao $v(t)$. In Fall, the switching off of $m(t)$ depends on the magnitude of $v(t)$. This is quite different from the weakly driven model.

\subsection{Stochastic Hybrid State Functional Model}

In the previous sections we have considered special cases of functional models. It has been found that the models generally contain 

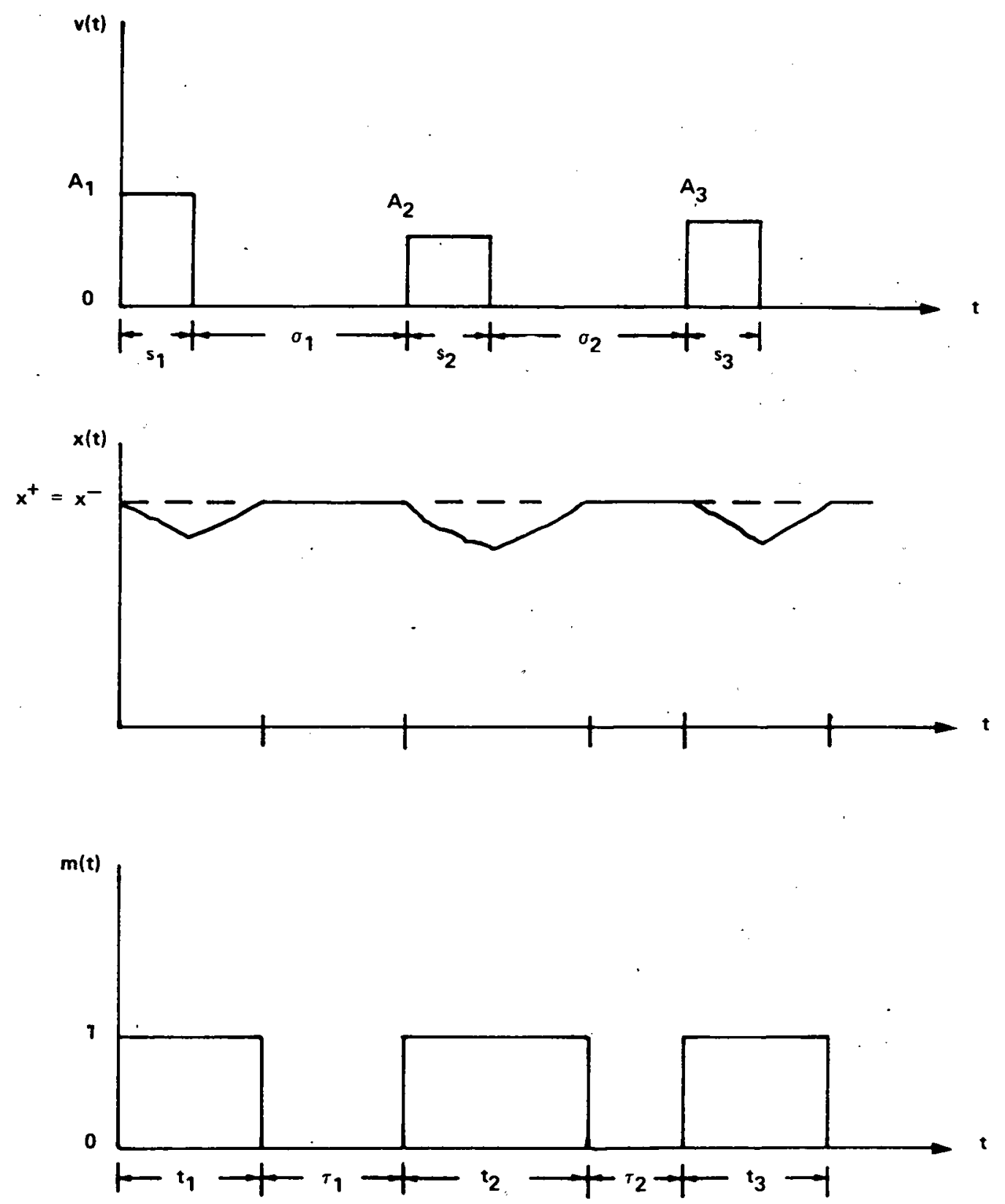

Figure 3.6 Evolution of $v(t), x(t)$, and $m(t)$ 
both continuous and discrete states, related to the state of energy storage. and the operating state of the electrical device respectively. Furthermore, the inputs into the functional model are stochastic processes corresponding to the service demands. In this section, we consider a general stochastic hybrid state model which includes all the special cases discussed earlier.

Given $p(t)$, the feedback from the electrical device model, each functional model is a dynamical system driven by $v(t)$, the service demand which is a stochastic process. The output process $m(t)$ is the electrical device operating state. While it is possible: for $m(t)$ to take on continuoue valuoc, the morc intereating case is wheu ul(L) is a jump process with a finite set of possible values. If one seeks a state variable. description, then two kinds of states will be present, a continuous state $x(t)$ and a discrete state $m(t)$ which also happens to the output. This type of model is a stochastic hybrid state system. We now consider a stochastic hybrid state functional model.

Let $x(t)$ be a $n$-dimensioned vector. Let the service demand $v(t)$ be of the form

$$
v(t)=\left[\begin{array}{l}
v_{1}(t) \\
v_{2}(t)
\end{array}\right]
$$

where $v_{1}(t)$ is a Wiener process and $v_{2}(t)$ a jump process. Both $v_{1}(t)$ and $v_{2}(t)$ may be vector-valued.

The continuous state $x(t)$ evolves according to the following stochastic differential equation

$$
d x(t)=f\left(x(t), m(t), v_{2}(t), t\right) d t+g\left(x(t), m(t), v_{2}(t), t\right) d v_{1}(t)
$$


where $f$ and $g$ are known functions. Note. that the dependence on $p(t)$ has been suppressed for the time being. The evolution of $x(t)$ thus depends on the driving processes $v_{1}(t)$ and $v_{2}(t)$ as well as on the discrete state $m(t)$. and sapplied power $p(t)$ which is included in the functions $f$ and $g$.

The discrete state $\mathrm{m}(\mathrm{t})$ takes values in a set.

$$
M=\left\{m_{1}, m_{2} \cdot \cdots \cdot \cdot\right\}
$$

which may be assumed to be finite. For the special cases considered before in the previous sections

$$
M=\{0,1\}
$$

The switching of $m(t)$ depends on the continuous state $x(t)$. In the most general form, the probability of transition of $m(t)$ from $m_{j}$ to $m_{i}$ at time $t$ depends on the past histories of both $x$ and $m$. This can be expressed as

$$
\operatorname{Pr}\left\{m(t+d t)=m_{i} \mid x^{t}, m^{t}, m(t)=m_{j}\right\}=\lambda_{i j}\left(x^{t}, m^{t}, t\right) d t
$$

where

$$
\begin{aligned}
& x^{t}=\{x(s), s \leq t\} \\
& m^{t}=\{m(s), s \leq t\} .
\end{aligned}
$$

$\lambda_{i j}$ is the instantaneous rate of transition $m_{j}$ to $m_{i}$ given $x^{t}$ and $m^{t}$.

In Figure 3.4, the two subsystems are thus described by equations (3.6.2) and (3.6.5) respectively. The model under consideration can be regarded as a generalization of the self-exciting jump process discussed in (10) since the evolution of $m(t)$ depends on its past. In the event that $\lambda_{i j}$ does not depend on $x(t)$, then the process is self-exciting. The study of jump processes has received a lot of attention recently (11-14) 
with the help of martingales. In our work, we shall adopt a more classical treatment .

In particular, we are interested in the situation where $\dot{m}(t)$ jumps from " $m_{j}$ to $m_{i}$ with probability one when $x(t)$ enters a certain set $x_{i j}$. This can be used to model the special cases discussed earlier. $\lambda_{i j}$ thus depends only on the instantaneous value of $x$ and is a Dirac delta or inpulse function. Alternatively, we can consider the integral of $\lambda_{i j}$. For a small interval dt

$$
\operatorname{Pr}\left\{m(t+d t)=m_{i} \mid x(t), m(t)=m_{j}\right\}=d \Lambda_{i j}(t+d t, t)
$$

where

$$
\begin{aligned}
d \Lambda_{i j}(t+d L, L)= & \Lambda_{i j}(L+d t)-\Lambda_{i j}(t) \\
& = \begin{cases}1 & x(t) \varepsilon x_{i j} \\
0 & x(t) \notin x_{i j}\end{cases}
\end{aligned}
$$

$\Lambda_{i j}(t)$ has a deterministic jump of 1 , whenever $x(t)$ enters $x_{i j}$ causing $m(t)$. Lu go from $m_{j}$ to $\ddot{m}_{i} \cdot \Lambda_{i j}(t)$ is thus a counting process for the $j$ to $i$ transition of $\mathrm{m}(\mathrm{t})$.

For the weakly driven functional model considered in Section 3.4 ,

$$
\begin{aligned}
& M=\{0,1\} \\
& x_{U 1}=\left\{x: x^{+} \geq x\right\} \\
& x_{10}=\left\{x: x^{+} \geq x\right\}
\end{aligned}
$$

The relationship between $x(t), \Lambda_{i j}(t)$ and $u(t)$ as shown in Figure.3.7. Intrepretation of the Hybrid State System

The solution of the nonlinear syslem described by equations (3.6.2) 

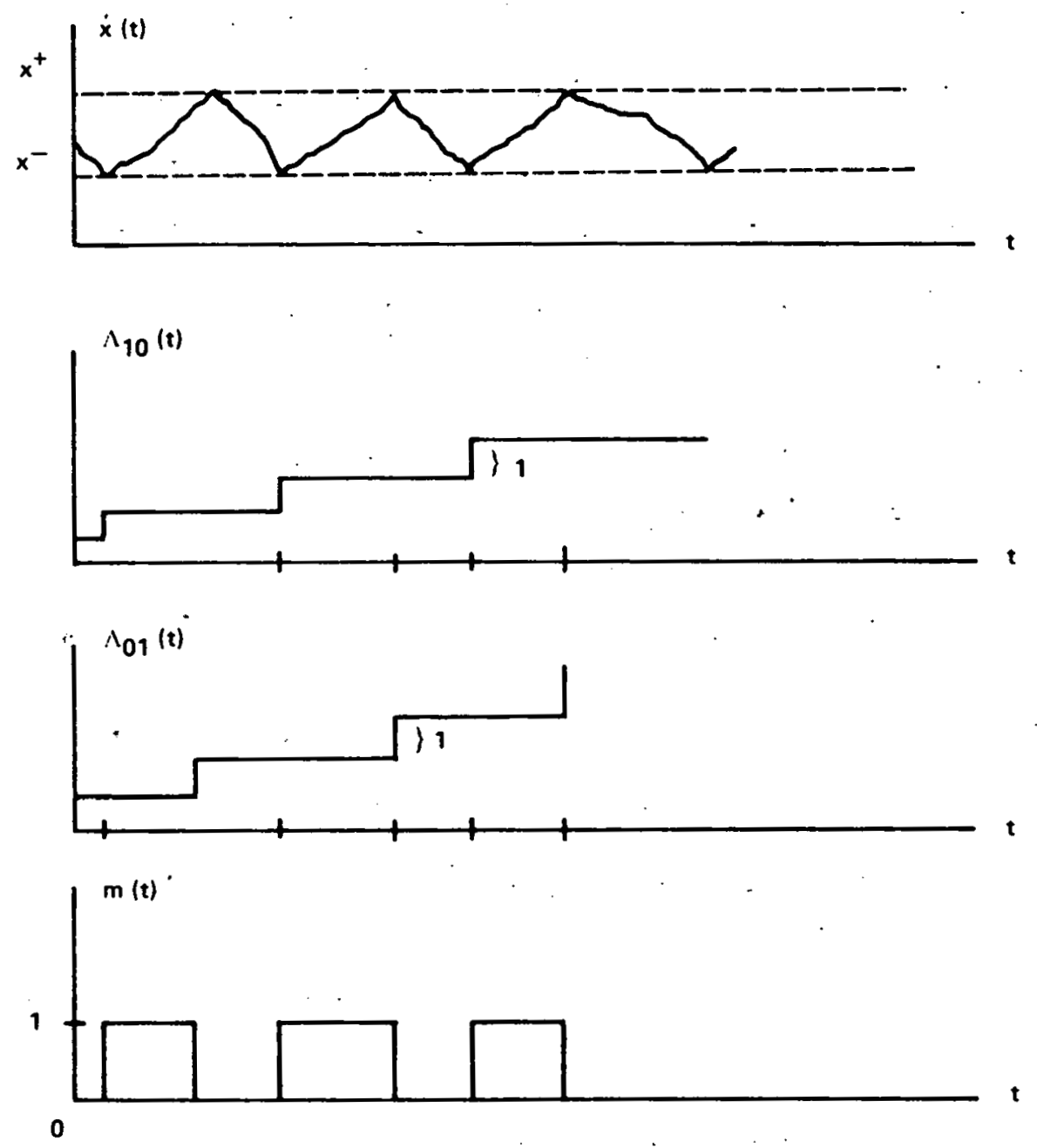

Figure 3.7 Relationship Between $x(t), \Lambda_{10}(t), \Lambda_{0 i}(t)$ and $m(t)$ 
and (3.6.5) can be intrepreted in the following way. Between the switching. instants $t_{0}$ and $t_{1}$ for $m(t), m(t)$ remains constant. We thus have an ordinary stochastic differential equation driven by a jump process $v_{2}(t)$ and a Wiener process $v_{1}(t)$. The interpretation of this equation is quite well known (15) Since almost all sample functions of $v_{2}(t)$ are constant except for a finite number of simple jumps in the interval $\left(t_{0}, t_{1}\right)$, the paths of $x($.$) are defined by joining the solutions of the equation between$ the jump points of $v_{2}(t)$. The overall solution is found by combining the solutions of $x(t)$ between the switchings of $m(t)$ which are triggered by $x(t)$

Tu characterize $m(x)$ furcher, we shall impose the tollowing additional assumptinns:

1. $M=\left\{m_{1}, m_{2}, \cdots, m_{|M|}\right\} \quad$ a finite set

2. $v_{2}(t)$ is a finite state Markov jump process with $S$ states, i.e.,

$$
\begin{aligned}
\operatorname{Pr}\left\{v_{2}(t+\Delta) \Rightarrow i \mid v_{2}(t)=j\right\}= & \left\{\begin{array}{l}
q_{i j} \Delta+o(\Delta) \quad i \neq j \\
1+q_{j j} \Delta+o(\Delta) i=j, i, j=1 \ldots, s
\end{array}\right.
\end{aligned}
$$

where $\quad \operatorname{lin}_{\Delta \rightarrow 0} \frac{o(\Delta)}{\Delta}=0$

Between the switching instants of $m(t),\left(x(t), v_{2}(t)\right)$ is a Markov process. To see this, let $t_{0}$ be the last switching instant for $m(t)$. For $t_{0} \leq s \leq t<t_{1}$, where $t_{1}$ is the next switching instant for $m(t), x(t)$ is a process uniqueiy determined by $x(s)$ and $v_{2}(s)$ for $s \leq u \leq t$. In fact, $x(t)$ is a Markov process. Also since $v_{2}$ is Markov, $v_{2}(u)$ for $u \geq 8$ is independent of $v_{2}\left(u^{\prime}\right), u^{\prime} \leq s$, when conditioned on $v_{2}(s)$. Thus $(x(t)$, 
$\left.v_{2}(t)\right)$ are independent of the random variables $\left(x\left(u^{\prime}\right), v_{2}\left(u^{\prime}\right)\right), u^{\prime}<s$ when conditioned on $\left(x(s), v_{2}(s)\right)$.

Characterization of $\mathrm{m}(\mathrm{t})$

Suppose the transition of $m(t)$ satisfies equation (3.6.7). Then, since $m(t)$ switches from $j$ to $i$ whenever $x(t)$ enters $x_{i j} m(t)$ is independent of $\left(x(u), v_{2}(u), m(u)\right), u<s$ when conditioned on $(x(s)$, $\left.\mathrm{v}_{2}(s), \mathrm{m}(s)\right)$. Thus $\left(x(t), \mathrm{v}_{2}(t), \mathrm{m}(t)\right)$ are jointly Markov.

We would like to characterize $m(t)$ as completely as possible. $m(t)$ can be regarded as a marked point process

(15) where the points correspond to the switchings and the marks correspond to the types of switching. One condition on the marks is that a $i j$ switching can only be followed by a $k i$ switching. As a result, the process is at least self-exciting. Alternatively, we can identify $m(t)$ with a multivariate point process where each component process represents one type of switching, for example, from $j$ to $i$. It is well known that a point process may be represented by means of a counting process. In the case of the multivariate point process representing $m(t)$, the corresponding counting process is $\Lambda_{i j}(t), i, j=1, \ldots$. Again, the point processes have to satisfy the constraint that an event $i j$ can only be followed by an event ki. $\Lambda_{i j}(t)$ is number of $i j$ marks (type $i j$ transitions) in the marked point process up to and including time $t$.

From the Markov property of $\left(x(t), v_{2}(t), m(t)\right)$, given that $m(t)$ switches into the discrete state $m_{i}$ from $m_{j}$ at $t=w_{i}$ with $x\left(w_{i}\right) \varepsilon x_{i j}$, the behavior of $m(t)$ for $t>w_{i}$ depends only on $x\left(w_{i}\right), v_{2}\left(w_{i}\right)$ and $m\left(w_{i}\right)=m_{i}$. $m(t)$ switches from $m_{i}$ to $m_{k}$ whenever $x(t)$ enters $x_{k i}$ first before entering olher sets $x_{s i}, s \neq k$. The interarrival time is thus related to the first passage time. The first passage time problem has been widely 
studied $(16-18)$. The probability of the interarrival time $t_{k i}$ from $m_{i}$ to $m_{k}$ is of the form

$$
\operatorname{Pr}\left\{t_{k i} \leq T \mid x\left(w_{i}\right), v_{2}\left(w_{i}\right), m\left(w_{i}\right)=m_{i}\right\}
$$

Thus, the interarrival time probability between two discrete states is a function of the initial state $x$ and $v_{2}$ at the last switching time, in addition to the two discrete states under consideration. From a physical point of view, this simply states that the switching dynamics of the discrete states can depend on the initial continuous state (energy storage) as well as the initial demand for energy.

The computation of first passage tiües lias been considered for simple one dimensional prohlems. For multidimensional problems of the type considered here, not much is known. Our discussion here is intended mainly to illustrate the dependence of the probability on the initial states, and its independence on what happens before.

\subsection{Special Cases}

We now look at the two special cases considered in Sections 3.4 and 3.5. In the weakly driven functional model considered in Section 3.4, the jump process $v_{2}(t)$ is absent. Thus we have

$$
-d x(t)=f(x(t), m(t), t) d t+g(x(t), m(t), t) d v_{1}(t)
$$

where $v_{1}(t)$ is a Wiener process. With $M_{,} x_{10}$ and $x_{01}$ defined as in equation (3.6.9), the characterization of $m(t)$ can be quite simple. Since the switrhing of u(t) dways occure at the flxed values of $x^{+}$os $x^{-}$, the $x\left(w_{i}\right)$ in equation (3.6.11) does not appear in the interarrival time probability. As a result, the interarrival times $t_{1}, t_{2}, \ldots$. , $\tau_{1}, \tau_{2}, .$. , etc., are independent random variables. $m(t)$ is then 
governed by an alternating renewal process. Alternatively, we can regard $m(t)$ as a marked point process, when the two marks are the two types of switchings. In either case, the point process is self-exciting and 1memory. If one restricts the attention to the arrival of demands, then the interarrival times $t_{1}+\tau_{1}, t_{2}+\tau_{2}$, . . , etc.," are independent random variables. As a result, the arrival of demands form a renewal process. This will be made use of in the aggregation of the demands in the next chapter. Note also that deterministic cycling of $m(t)$ occurs if $v_{1}(t)=0$.

In the strongly driven functional model considered in section 3.5, the Wiener process $v_{1}(t)$ is absent. The continuous state $x(t)$ thus evolves according to

$$
d x(t)=f\left(x(t), m(t), v_{2}(t), t\right) d t
$$

where $\mathrm{v}_{2}(t)$ is a Markov jump process. With $M, x_{10}$ and $x_{01}$ defined as in equation (3.6.9), the switching of $\mathrm{m}(\mathrm{t})$ again always occurs at the fixed values of $x^{+}$and $x^{-}$. Thus the interarrival time probability only depends on $v_{2}$ at the last switching instant. This is obvious from the situation displayed in Figure 3.6. This dependence on $v_{2}$ implies that the interarrival times are no longer independent random variables and $m(t)$ is not an alternating renewal process. If we regard $\mathrm{m}(\mathrm{t})$ as a marked point process, it is 1 memory and excited by $v_{2}(t)$.

It can be shown that if $v_{2}(t)$ is not a Markov process, then the interarrival time probability will depend on how long $v_{2}(t)$ has been in that state in addition to the actual state at the switching instant of $m(t)$. The Markov assumption of $v_{2}(t)$ makes it possible to forget the values of $v_{2}(t)$ before the switching instant. 


\subsection{Intre $\quad \Omega$}

In this chapter we shall consider the aggregation of functional models. The overall objective of this project is to obtain an aggregated model for the electrical power demand of a large number of component loads. For the individual component load model, we have decomposed it into a functional model and an electrical device model. The functional model relates the operating state of the electrical device to the external influence factors while the electrical device model relates the actual power demand to the voltage and frequency of Llie supply given that the device is on.

The same philosophy will be adopted for the aggregated model. We shall consider an aggregated functional model which relates the aggregated functional state of a large number of identical devices to the external influence factors given the power supplied from the electrical portion of the components. They will be interconnected with the aggregated electrical devíce módel to be considered later to give the aggregated load model. This decomposition is illustrated in Figure 4.1.

The inputs into the aggregated load model are influence factors which are common to all the components being aggregated, such as weather, system voltage and frequency.

In the next section we shall consider the basic assumptions behind the aggregated functional model. This will be followed by the aggregation of the general functional states $\mathrm{m}(t)$ to give multivariate Pnisan frocess. We then consider an alternative approach to the special cases of the 


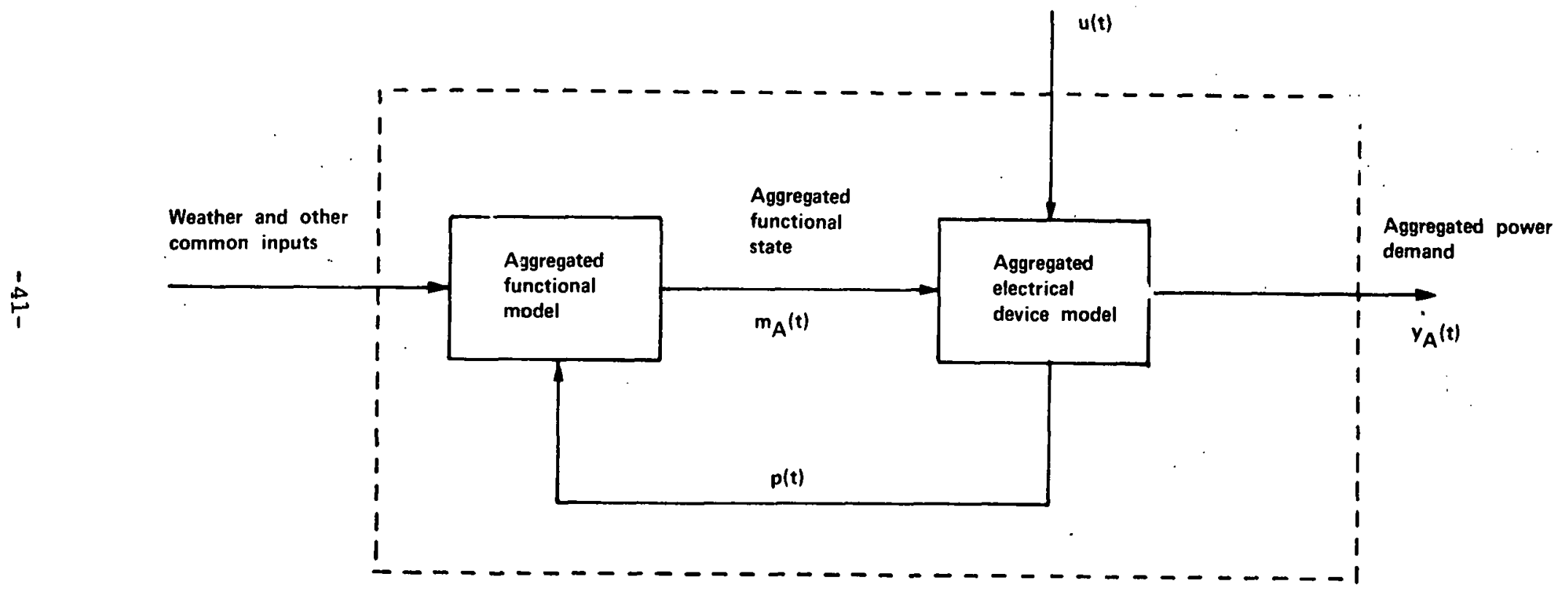

Aggregated component load model

Figure 4.1 Decomposition of aggregated load model 
memoryless and weakly driven cases and consider its applicability to the strongly driven case.

\subsection{Assumptions of the Aggregated Model}

We shall consider a radial network connected to a large number of components. It is desired to find the aggregated functional state at the common supply node. Since components with different characteristics are involved, the degree of aggregation is not fixed a priori. We shall partition the components into classes with identical models, with an aggregated functional model for each class. In particular, memoryless, weakly driven and strongly driven functional models will not be mixed in the àggregation, but will have distinct aggregated models.

The Cundamencal funcrional model aggregacion problem is then the following:

Given $m_{1}(t), \cdot$, $m_{K}(t)$, the functional states of a large number of identical systems in the same class, find $m_{A}(t)$, the aggregated functional state of the class.

$$
m_{A}(t)=\sum_{k=1}^{K} m_{k}(t)
$$

From Figure 2.2, it can be seen that each individual functional model has two inputs, $v_{k}(t)$ and $p(t)$. In the aggregation procedure, $v_{k}(t)$ is assumed to be a stochastic process with known statistics depending on weather and time of the day, etc. The $v_{k}(t)$ 's for different components are assumed to be independent. $p(t)$ is assumed to be a deterministic input. Each of the individual $\mathrm{m}_{k}(t)$ 's is a stochastic process whose statistics depend on weather, time of the day, and $p(t)$. The same will hold for the aggregated functional state $\mathrm{m}_{A}(t)$. Thus the aggregated functional model 


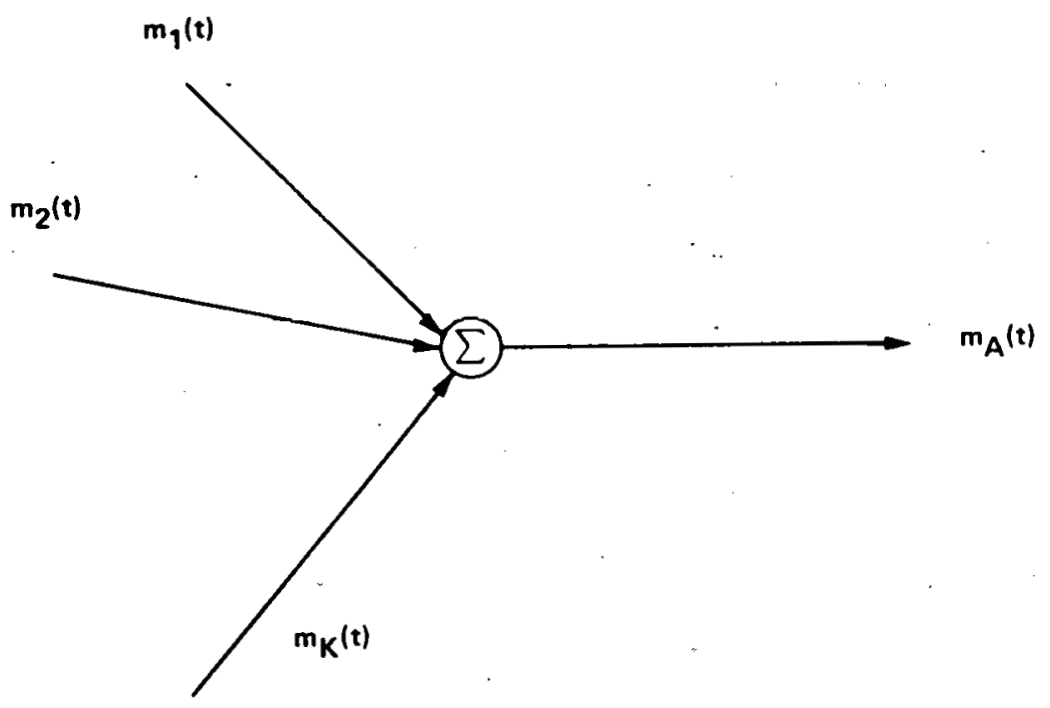

Figure 4.2 Aggregation of Functional Models 
can be used to study the effect of weather and time of the day on the functional states. The effect of a change in the supply voltage or frequency can also be investigated since $p(t)$ will be affected through the aggregated electrical device model.

While much of the results in this chapter can be generalized to nonboolean functional states, our attention is primarily on devices which may be either on or off, i.e., $m_{k}(t)=1$ or $0 . m_{A}(t)$, the aggregated functional state then describes the number of devices of a certain class which are connected electrically to the power system at any time.

\subsection{Aggregation of the General Functional Model}

In Chapter 3, we have discussed the characterization of $m_{k}(t)$ as a marked point process where the occurrence times of the point process correspond to the switching times and the marks correspond to the type of transition. We now restrict our attention to the case when $m_{k}(t)=1$ or 0 , i.e., the device can only be either on or off. Let $\left\{N_{k}(t)\right.$; $\left.t \geq t_{0}\right\}$ be a counting process indicating the total number of switchings in the interval $\left(t_{0}, t\right)$ regardless of the mark. Let $z_{i}=1$ or -1 be the marks corresponding to an on or of transition at the ith occurence time. Then

$$
m_{k}(t)=\sum_{i=0}^{N_{k}(t)} z_{i}
$$

is the mark accumulator process. See Figure 4.3 for the relationship between the marked point process and its accumulator process. Note that a marked point process and its accumulator process are equivalent whenever 0 is not a possible value of the mark. The aggregation process is then the 


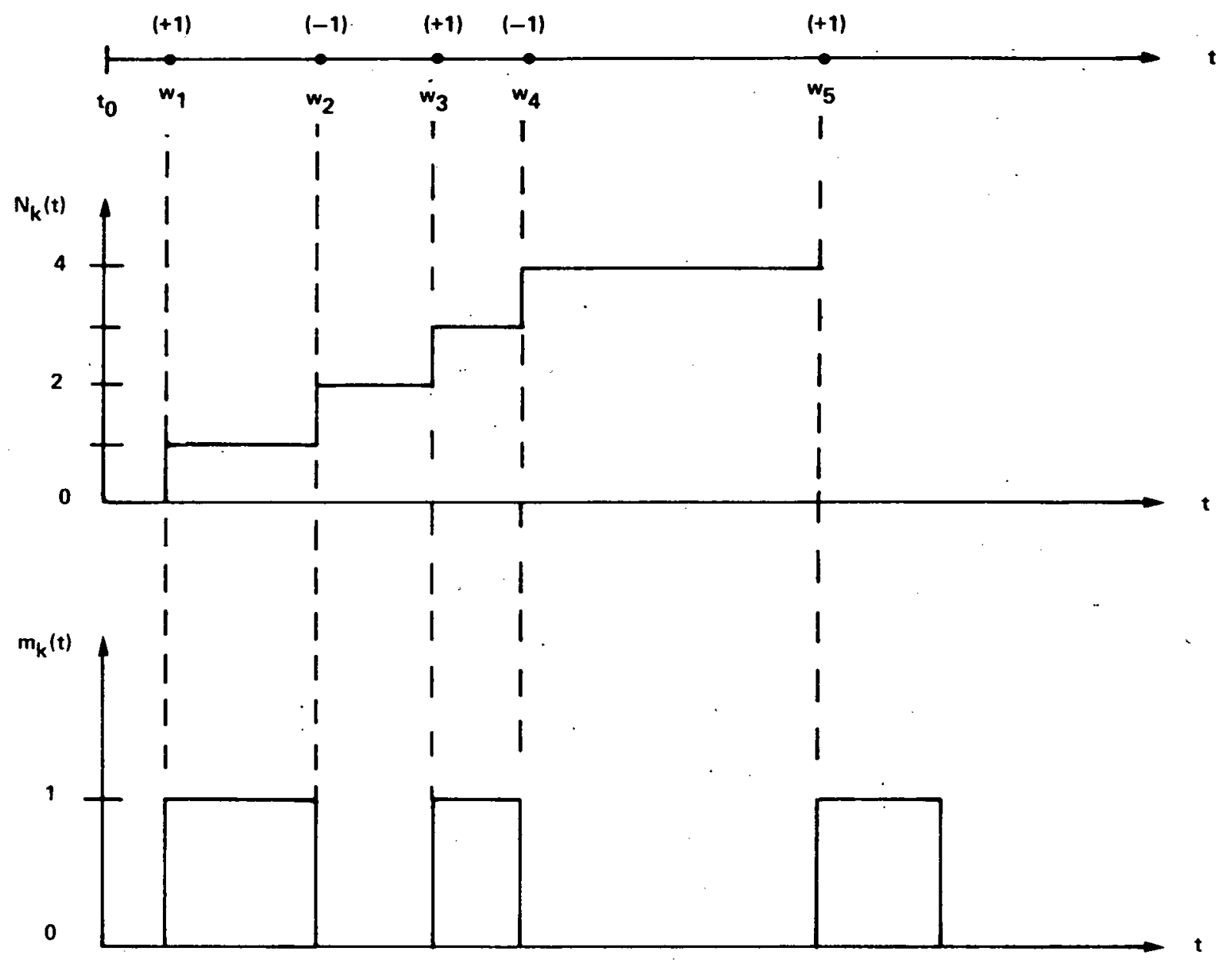

Figure 4.3 The marked point process and its mark accumulator process $m_{k}(t)$ 
characterization of the sum of a large number of independent marked point. processes.

With a finite set of marks as considered in the functional model, it is sometimes more convenient to consider the representation in terms of a multivariate point process where each component process represents one type of switching. In Figure 4.3, the two component processes will have occurrence times at $w_{1}, w_{3}, w_{5}, . .4$, and $w_{2}, w_{4}, w_{6}, . .$. , respectively. The mark associated with the two processes are +1 and -1 . The counting processes for these are $\Lambda_{10}(t)$ and $\Lambda_{01}(t)$. Note that for any particulá lóal

$$
\begin{aligned}
& N(t)=\Lambda_{10}(t)+\Lambda_{01}(t) \\
& m(t)=\Lambda_{10}(t)-\Lambda_{01}(t)
\end{aligned}
$$

As the first step of the aggregation procedure, we shall consider the supposition or pooling of a large number of multivariate point processes. The superposition or pooled point process will determine the behavior of the class of component functional models. This is illustrated in Figure 4.4. Under certain weak conditions, the pooled process converges to: a multivariate Poisson process.

$$
\text { Let } \underline{N}_{n i}(t)=\left\{N_{n i}^{1}(t), \ldots ., \text { iv }_{n i}^{r}(t)\right\} t \geq t_{0}, i=1, \ldots, k_{n} \text { be }
$$
counting processes for independent, r-variate point processes. Let $\underline{N}(t)$ $=\left\{N^{l}(t), . ., N^{i}(t)\right\}$ be the counting process for an r-variate Poisson process, where $\mathrm{N}^{1}, \ldots, \mathrm{N}^{\mathrm{r}}$ represent independent Poisson processes with mean functions $\Lambda(t)=\left\{\Lambda^{1}(t), \ldots,, \Lambda^{\mathrm{T}}(t)\right\}$. The following theorem, found in references $(19,20)$, is stated without proof. 


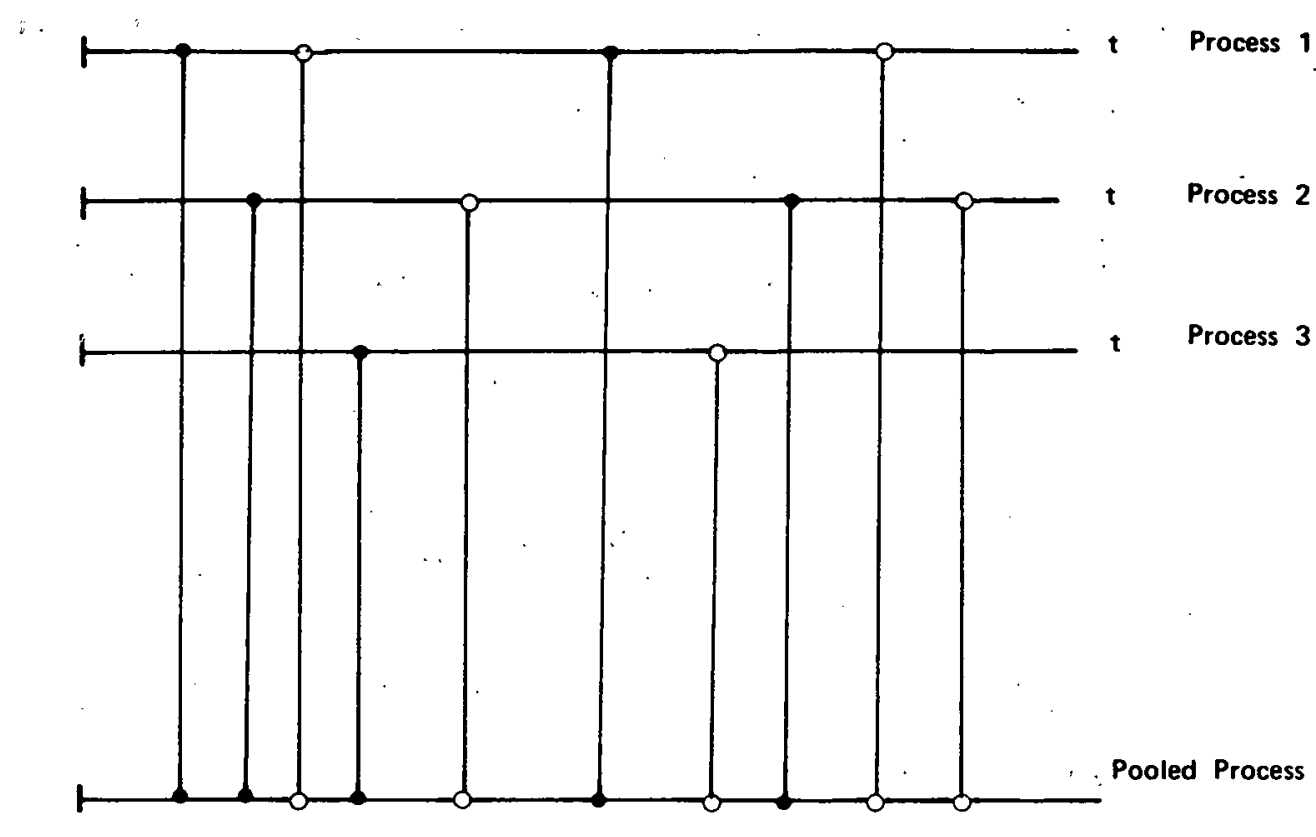

- points in first component (on)

0 points in second component (off)

Figure $4.4^{-}$Superposition of multivariate point processes 
Theorem 4.1

Suppose for every $t>t_{0}$

$$
\lim _{n \rightarrow \infty} \quad \sup _{1 \leq i \leq k} \quad \operatorname{Pr}\left[\sum_{j=1}^{r} N_{n i}^{j}(t)>0\right]=0
$$

Then the superposition process $\underline{N}_{n}(t)=\sum_{i=1}^{k} \underline{N}_{n i}(t)$ converges weakly, i.e., in distribution to the Poisson process with mean functions $\Lambda$ ( $t)$ if and only if for every $t>t_{0}$

$$
\begin{aligned}
\lim _{n \rightarrow m} & \sum_{i=1}^{k} \operatorname{Pr}\left[N_{n i}^{j}(t)>0\right]=\Lambda^{j}(t) \\
j & =1, \ldots, r \\
\lim _{n \rightarrow \infty} & \sum_{i=1 .}^{k} \operatorname{Pr}\left[\sum_{j=1}^{r} N_{n i}^{j}(t)>1\right]=0
\end{aligned}
$$

Equation (4.3.4) is called the uniform sparseness condition. This theorem simplifies considerably when the processes are stationary. The error of approximating a large but finite number of point processes by a Poisson process is also considered in ${ }^{(19)}$.

When this theorem is applied to a large number of $m_{k}(t)$ ' a viewed as '2variate point processes, $m_{A}(t)$, the aggregate functional state, is then approximately characterized by a 2-variate Poisson process. The two independent component processes determine the Limes at whith a now electrical device is turned on, i.e., $m_{A}(t)$ increases by 1 , and the times at which an electrical device is turned off, i.e., $m_{A}(t)$ decreases by 1 . Note that while for each individual electrical load, $m_{k}(t)$ alternates between 0 and $1, m_{A}(t)$ can have consecutive positive or negative excursions of 1. The two component processes may have different incensity funcliuns 
when more electrical devices are being turned on than off or vice versa. The intensity functions will also be functions of time, depending on the time of the day. Furthermore, they are also functions of $p(t)$, the power supplied from the electrical device model. When $p(t)$ is changed, the aggregated functional state will behave in a different manner.

When the 2-variate Poisson process is known, it is then possible to. predict the number of electrical devices which will be turned on-off in the near future. The dependence of the parameters of the process on the supplied $p(t)$ enables the utility to evaluate the effects of load management schemes. Phenomena such as "fly-back"(21) describing the sudden increase in the load factor of a group of water heaters when they are turned on after being kept off under load management can then be investigated. Such investigations are necessary before load management schemes can be evaluated in a rational manner.

\subsection{Special Cases}

We now consider the special cases of the memoryless and weakly driven functional models where the aggregated functional model can be obtained by a difference approach.

It has been shown in Section 3.7 that the arrival of electrical demands, i.e., the turning on of the functional states for each individual component is a renewal process in the weakly driven functional model. The same is true for the memoryless functional model. Consider a class of memoryless or weakly driven functional models. The instants at which a new demand of electricity arrives for the entire class are the superposition of the individual independent renewal process. By a specialization of Theorem 4.1 or the results in ${ }^{(19)}$, it is well known that as $K$ increases, 
the pooled process describing the switching on of functional states approaches a Poisson process with intensity function $\lambda(t)$.

Let $w_{i}$ be the occurrence times in this Poisson process and $N(t)$ be the number of occurrences in the interval $\left(t_{0}, t\right)$. Let $T_{i}$ be the duration of the ith electrical demand, i.e., the functional state which is turned on at $w_{i}$ is turned off at $w_{i}+\tau_{i}$. Then

$$
m_{A}(t)=\cdot \sum_{k=1}^{K} m_{k}(t)=\sum_{i}^{N(t)} h\left(t-w_{i} ; \tau_{i}\right)
$$

where $h$ and the superposition process $m_{A}(t)$ are shown in Figure 4.5. For latge $\mathrm{K}, \mathrm{II}(\mathrm{t})$ is Llius a filiered Polsson process ilil with mean $\gamma_{1}(t)$ and variance $y_{3}(t)$ given by

$$
\begin{aligned}
& \gamma_{1}(t)=\int_{t_{0}}^{t} \lambda(w) E(h(t-w ; t)) d w \\
& \gamma_{1}(t)=\int_{t_{0}}^{t^{0}} \lambda(w) E\left(h^{2}(t-w ; t)\right) d w
\end{aligned}
$$

The following certral limit theorem $(10)$ for filtered Poisson processes can then be used.

Theorem 4.2

$$
\text { Suppose } \gamma_{1}(t)<\infty, \gamma_{2}(t)<\infty
$$

$$
\text { and } \frac{\Gamma\left(t_{1}, \tau_{2}, \tau_{3}\right)}{\left(\gamma_{2}\left(t_{1}\right) \gamma_{2}\left(t_{2}\right) \gamma_{2}\left(t_{3}\right)\right)^{\frac{1}{2}}}
$$

tends to zero unitormly on $\left(t_{0}, T\right) \times\left(t_{0}, T\right) \times\left(t_{0}, T\right)$ as certain parameters tend to prescribed limits, where 

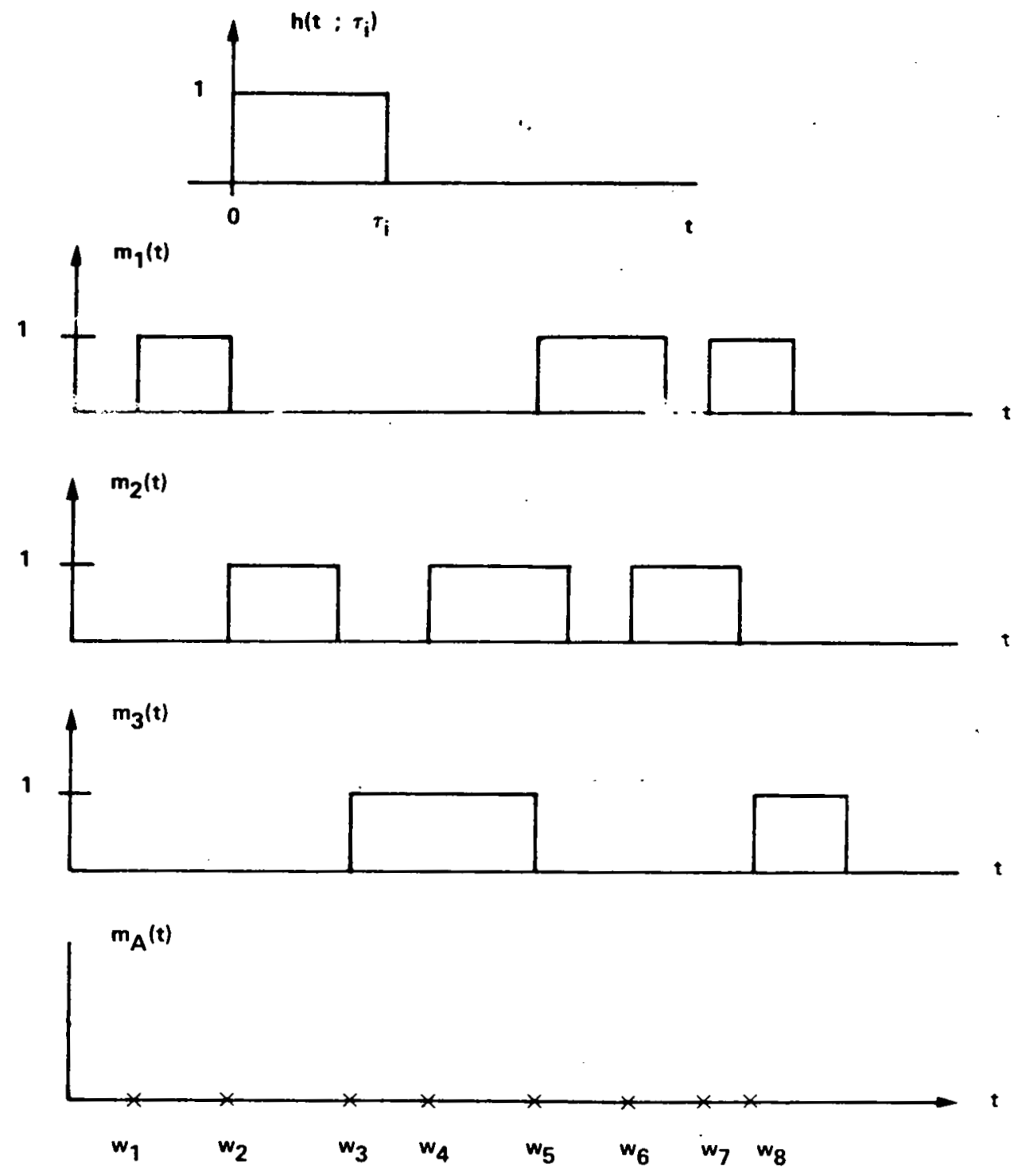

Figure 4.5 Superposition of $m_{k}(t)$ 


$$
\begin{aligned}
& \Gamma\left(t_{1}, t_{2}, t_{3}\right) \triangleq \\
& \int_{t_{0}}^{\min \left(t_{1}, t_{2}, t_{3}\right)} \lambda(w) E\left\{\left|h\left(t_{1}-w ; \tau\right) h\left(t_{2}-w ; \tau\right) h\left(t_{2}-w ; \tau\right)\right|\right\} d w \\
& \text { Then } m^{*}(t) \triangleq \frac{m_{A}(t)-\gamma_{1}(t)}{\gamma_{2}^{\frac{1}{2}}(t)} .
\end{aligned}
$$

tends to a Gaussian process on $\left(t_{0}, T\right)$ with zero mean and covariance

$$
\frac{\int_{t_{n}}^{\min \left(t_{1}, t_{2}\right)} \lambda(w) E\left[h\left(t_{1}-w ; \tau\right) h\left(t_{2}-w ; \tau\right)\right] d w}{\left[\gamma_{2}\left(t_{1}\right) \gamma_{2}\left(t_{2}\right)\right]^{\frac{1}{2}}}
$$

This theorem indicates that as $\mathrm{K}$ increases, $\mathrm{m}_{\mathrm{A}}(t) \overline{\mathrm{j}}$ can be viewed as a Gaussian random process with known statistics. Note that it is obvious that for any $t, m_{A}(t)$ being the sum of independent random variables, will approach a Gaussian random variable. Theorem 4.1, however, characterizes the dynamic behavior of $m_{\Lambda}(t)$.

When we try to apply the same philosophy to the strongly driven functional model, it is found that the aggregated process $m_{A}(t)$ cannot be viewed as a filtcred poioson proccoo. Thio io oo oince the ladividual $m_{k}(t)$ 's are not filtered point processes. If we look at Figure 3.6, we see that although the switching on of $m_{k}(t)$ can be viewed as a renewal process, the switching-off may depend on several arrivals of $v(t)$. when the next water demand is initiated before the temperature reaches the thermostat value. 


\section{ELECTRICAL DEVICE RESSPONSE MODELS}

\subsection{Introduction}

This chapter is concerned with the aspect of modeling the aggregate behavior of loads served by a feeder in response to fluctuations in feeder voltages and frequency. For relatively slow and relatively $\mathrm{sm}$ all fluctuations in $\mathrm{V}$ and $\mathrm{f}$ (voltage and frequency, respectively), quasi steady-state performance is postulated. For either large or fast fluctuations a dynamic response model may be necessary.

The primary applications of response models are those which require prediction of syste $m$ behavior for control and for security related functions. We cite here three in ajor possible areas

- steady-state security analysis

- transient security analysis

- automatic generation control ( $A G C$ )

In steady-state security analysis, load-flow analysis is conducted for given outage contirgencies. Traditionally, classical load flow models are used whereby load busses are represented as constant $(P, Q)$ nodes. In the context of loadresponse modeling, and under steady-state conditions,

$$
\begin{aligned}
& p=P(V) \\
& Q=Q(V)
\end{aligned}
$$

By appropriately identifying such load-response functions for each load bus, contingency analysis can be performed more realistically.

In transient sensitivity analysis, the load response model will have the form: 


$$
\begin{aligned}
& P=P(V, f) \\
& Q=Q(V, f)
\end{aligned}
$$

Under certain conditions, dynamic effects cannot be neglected, and in this case, one will require:

$$
\begin{aligned}
& P=P(V, f, x) \\
& Q=Q(V, f, x)
\end{aligned}
$$

Where $\mathrm{x}$ is a state vector of known dyna in ics

$$
\frac{d x}{d t}-[(x, v, f)
$$

In aurnmatic poneration control ( $\triangle C G$ ), we turjeclure liat volrage and frequency dependence will be sufficient exccpt in special cases of large motors.

Large vulcage (and frequency) fluctuations, cven if relatively slow, can have various response impacts, the most important of which is the switching off of certain devices. In these cases, restoration of nor $\mathrm{m}$ al service is not instantaneous.

In this chapter, we shall address first the quasi steady state asper.t of the proble $m$ and then discuss the issues of dynamic and nonlinear asperts later:

\section{\$.2 Aggregation of Elcctrical Devices (3Leduly-gLale)}

Based on the decomposition of electrical and functional models discussed in Chapter III, the functional models will be able to predict the statistics of the status of electrical devices. They can also predict statistics of loading levels for variable-load devices (e.g., loads on elevators). For steady-state representation of lood reaponse, both real and reactive device loads will be functions of frequency and voltage. In order to be able to aggregate many devices, we shall require the following 
- (a) For each device class the normalized (i.e., per unit) functional dependence is fixed. In a sense this is an implicit definition of a device class.

(b) Functions of voltage and frequency should be of the same type across all device classes (e.g., polynomials).

The first requirement will ensure that the coefficients (parameters). of a device's functional dependence on voltage and frequency are constant for each device class. The second requirement will ensure that aggregation over many device classes, to obtain an overall load-response characteristic is possible.

In order to illustrate our point, we shall postulate the use of polynomials for a device response characteristic. Given this postulate we proceed as follows:

Definitions

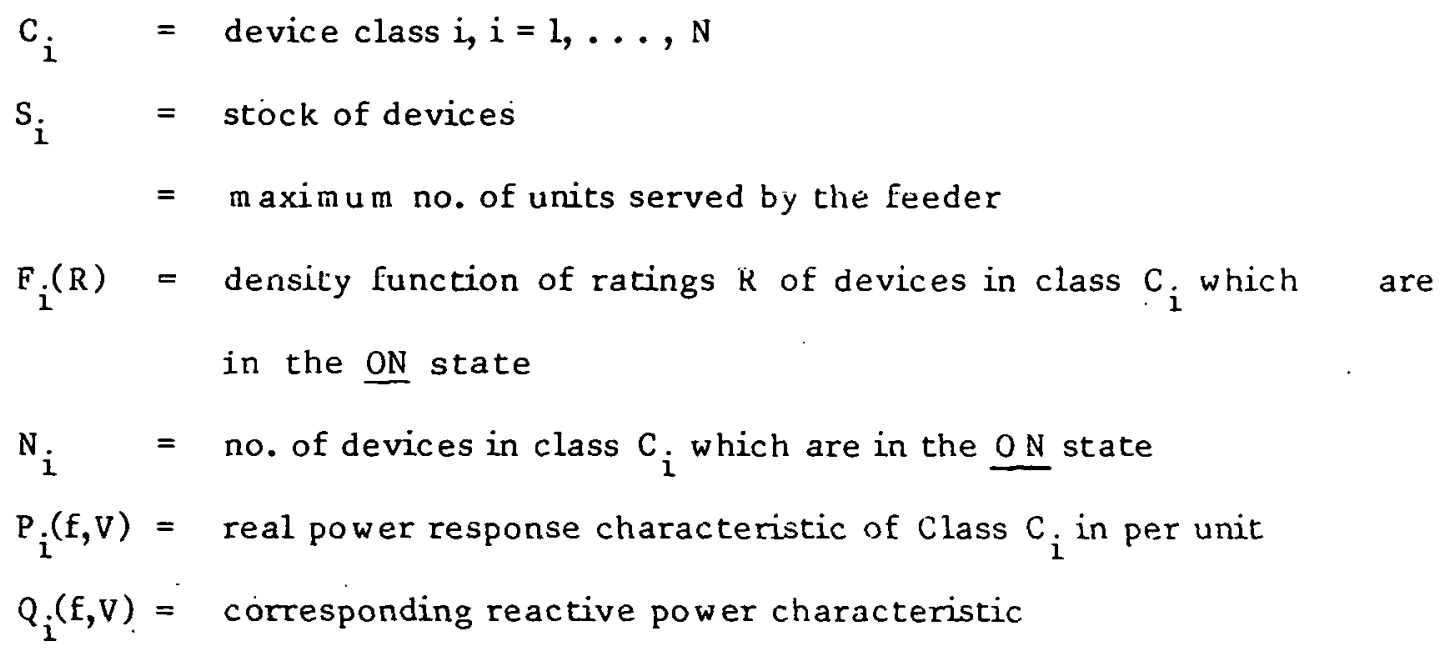

Given the above definitions, it is easy to obtain the average response characteristic of class $C_{i}$ devices:

$\bar{P}_{i}=R e a l$ power average output of all $C_{i}$ devices 


$$
\begin{aligned}
& =N_{i} \int_{R_{\min }}^{R_{\max }}\left(F_{i}(R) R \quad P_{i}(f, v)\right) d R \\
= & N_{i} \bar{R}_{i} P_{i}(f, V)
\end{aligned}
$$

Similarly,

$$
\bar{Q}_{i}=N_{i} \bar{R}_{i} Q_{i}(f, V)
$$

where $\bar{R}_{i}$ is the average rating of devices $C_{i}$ in the $O N$ state. The density function $F_{i}(R)$ and iv are obtainable from analysis of functional models for the given dievire rlass.

In aggregating nuer several hevire rlassea, the pnlynnmial approvimations of $P_{i}(f, V)$ and $Q_{i}(f, V)$ will be used, as a first step:

$$
\begin{aligned}
& P_{i}(E, V)=P_{o i}+a_{1 i} V+a_{2 i} f+a_{3 i} V^{2}+a_{4 i} f^{2}+a_{5 l} f V+\ldots \\
& A s \quad a \text { result, when aggregating over several device classes served by }
\end{aligned}
$$
the feeder, one obtains:

where

$$
\begin{aligned}
\bar{P}(f, v) & =\sum_{i=1}^{N} \bar{P}_{i}(f, v) \\
& =\sum_{i=1}^{N} N_{i} \bar{k}_{i} P_{i}(\bar{f}, v) \\
& =\bar{P}_{0}+\bar{a}_{1} v+\bar{a}_{2} f+\ldots
\end{aligned}
$$

$$
\begin{gathered}
P_{0}=\sum_{i=1}^{N} P_{01} N_{1} \bar{R}_{1} \\
\bar{a}_{j}=\sum_{i=1}^{N} a_{j i} N_{i} \bar{R}_{i} \quad j=1,2, \ldots
\end{gathered}
$$

A similar set of expressions are valid for the reactive power component. In this manner, the determining factoris of the overall steeady-state load response characteristics are: 

(a) Expected number of operating devices in each class $\left(\mathrm{N}_{\mathrm{i}}\right)$
(b) Average ratings of operating devices $R_{i}$
(c) Coefficients of device class response function ( $P_{i o}, a_{i j}$ )

The first two sets of numbers are obtainable from the functional models associated with the device. The last set of coefficients are obtainable either analytically or experimentally.

Another quantity of irterest will be the variance of the load due to uncertainties in $\mathrm{N}_{i}$ and ratings of the devices

Define

$$
\begin{gathered}
\bar{N}_{i}=E \cdot\left(N_{i}\right) \\
\sigma^{2} N_{i}=E\left[\left(N_{i}-\bar{N}_{i}\right)^{2}\right] \\
\sigma_{R_{i}}^{2}=E\left[\left(R_{i}-\bar{R}_{i}\right)^{2}\right]
\end{gathered}
$$

Using these definitions, we can write

$$
\begin{aligned}
\sigma_{P_{i}}^{2} & =\text { variance of power demand fur class } C_{i} \\
& =E\left[\left(N_{i} R_{i} P_{i}-N_{i} \bar{R}_{i} P_{i}\right)^{2}\right] \\
& =N_{i}{ }^{2} P_{i}{ }^{2} E\left[\left(R_{i}-\bar{R}_{i}\right)^{2}\right] \\
& =N_{i}{ }^{2} P_{i}{ }^{2} \sigma^{2} R_{i}
\end{aligned}
$$

This expression lus the varianee of powcr demand suggests im mediately that the range of device ratings in the class should be $s m a l l$, i.e., $\sigma_{R_{i}}$ should be small, in order for $\sigma_{\mathrm{P}_{i}}$ to be small. Obviously, from. Eq. (5.2.3) one concludes:

$$
\sigma_{P_{i}}=N_{i} P_{i} R_{i}
$$

Generalizing the above result to total denand over all classes, the 
result is.

The standard deviation, consequently, is

$$
\begin{aligned}
\sigma^{2} \bar{P} & =\sum_{i=1}^{N} \sigma^{2} P_{i} \\
& =\sum_{i=1}^{N} N_{i}{ }^{2} P_{i}{ }^{2} \sigma^{2} R_{i}
\end{aligned}
$$

$$
\sigma \overline{\mathrm{P}}=\left[\sum_{i=1}^{N} \mathrm{~N}_{i}{ }^{2} \mathrm{P}_{i}{ }^{2} \sigma^{2} \mathrm{R}_{i}\right]^{\frac{1}{2}}
$$

The above result assumes statistical independence among device classes when it comes to the distributions of device ratings.

\subsection{Examples of Component Response Mndels}

(a) Fila ment Lampe and Element Heaters (23)

Filament lamps and element heaters behave as pure resistance, varying somewhat with voltage but virtually independent of operating frequency. When applied voltage varies, active power requirement changes in proportion to the nth power of the voltage, while the reactive power remains zero. Hence with per unit notation,

$$
\begin{aligned}
& P=V^{n} ; Q=0 \\
& \frac{d P}{d V} n V^{m-1}=m \frac{P}{V} \\
& \frac{d P}{d \omega}=\frac{d Q}{d \omega}=\frac{d Q}{d V}-0
\end{aligned}
$$

The value of the exponent $n$ ranges from 1.55 to 1.60 for mudern fila incnt la mps and 2.0 for ele ment heaters.

(b) Discharge Lamps

Discharge lamps of all classes have one characteristic in common, 
that the lamp cannot be operated directly from the supply. The arc discharge having a negative resistance characteristic requires a current limiting device for stable operation. To' start a discharge lamp a higher voltage than the normal supply is usually required to establish ionization. In many cases the ballast or choke provides the starting voltage and subsequently limits the current. This current-limiting equipment introduces some power loss and lowers the power factor of the installation. Power factor correction by capacitors is ordinarily used and the operating power factor of discharge lamp loads range from 90 to .98 lagging, depending on the efficiency of the choke and capacitors.

The input reactance varies directly with frequency and the effective input resistance is both frequency and current dependent. The active power input to the circuit may increase as the frequency is increased above nominal value, which means that the tube resistance. decreases. The reactive power input-depends on the amount of shunt compensation present. For the purpose of analysis the assumption. is made that the voltage drop across the tube re m ains constant.

The approximate expressions developed for the characteristic coefficients are,

$$
\begin{aligned}
& \left.\frac{\mathrm{dP}}{\mathrm{dV}}\right|_{\omega=c}=\frac{P_{0}}{V}\left(\frac{1}{1-\cos ^{2} \phi_{t}}\right) \\
& \left.\frac{\mathrm{dP}}{\mathrm{d} \omega}\right|_{V=c}=\frac{P_{0}}{V}\left(\frac{1}{1-\cos ^{2} \phi_{t}}-3\right) \\
& \frac{\mathrm{dQ}}{\left.\mathrm{dV}\right|_{\omega=c}}=\frac{2 Q_{0}}{V}\left(1+\frac{P_{0}}{Q_{0}} \cot \phi_{t}\right) \\
& \left.\frac{d Q}{d \omega}\right|_{V=c}=\frac{C_{0}}{\omega}\left(1+4 \frac{P_{0}}{Q_{0}} \cot 2 \phi_{t}\right)
\end{aligned}
$$


where $\cos \phi_{t}$ is the power factor without shunt compensation.

(c) Arc Furnace

With fair accuracy, 2 three phase arc furnace can be treated as a balanced three phase star connected load and can te represented approximately by an ac series circuit consisting of

(1) A fixed inductance $\mathrm{L}$ accounting for the inherent inductance of the fumace transformer, the supplementary or buffer reactor and the inductances of the furnace cables and bus bars,

(2) A fixed resistance representing resistance in transformer windings, cables, hus hars and the clcctrode, and

(3) A variable resistance representing the arc itself. (26)

The all resistance is current dependent, falling when the current riscs such that a reduced arc voltage results. Considering the voltage drop across the lotal effective resistance of the circuit, the fall in arc voltage due to rise in current is approximately compensated for by the increase voltage drop due to resistance of the main transformer, buffer reactor, fumare transformer, lcad and elecluudes. In this way the voltage drop across the effective resistance $R$ of the rircuit bccomca approximarely constant. This implies that $R$ is proportional to the inverse of the current and input power is proportional to furnace current.

The expressions developed for the characteristic coefficients are as follows,

$$
\begin{array}{ll}
\left.\frac{\mathrm{dP}}{\mathrm{dV}}\right|_{\omega=\mathrm{c}}=\frac{\mathrm{BVP}}{\omega \mathrm{L} \varphi_{\mathrm{O}}} ; & \left.\frac{\mathrm{dQ}}{\mathrm{dV}}\right|_{\omega=\mathrm{c}}-\frac{2 \mathrm{BV}}{\omega \mathrm{L}} \\
\left.\frac{\mathrm{dP}}{\mathrm{d} \omega}\right|_{V=\mathrm{C}}=-\frac{\mathrm{P}}{(1)} ; & \left.\frac{\mathrm{d} Q}{\mathrm{~d} \omega}\right|_{V=c}=-\frac{\mathrm{P}_{\mathrm{O}}}{\omega}
\end{array}
$$


where $B$ is the transformer off-nominal turns ratio.

(d) Converter

Large static converters have been used in recent years in connection with high voltage transmission links. In system studies involving industrial loads where converters are sometiries used extensively, they have been represented simply by shunt impedances, independent of frequency.

Neglecting any counter emf in the load, steady state operation of the static converter can be represented with reasonable accuracy using the simple series $L R$ aodel, subject to the constraints of the operating model. Inductance $L$ and resistance $R$ are considered constant.

By controlling the firing angle, converters can be operated either for constant current output or for constant voltage output. By far the largest field of applications of static converters at present is in the electrochemical process industries, where the rectifier operate in the constant current mode. Power input to the converter and the characteristic coefficients for this mode of operation have been ierived as follows:

$$
\begin{array}{ll}
\left.\frac{d P}{d V}\right|_{\omega=c}=\frac{P_{0}}{V}\left(1+\left(\frac{Q_{0}}{P_{0}}\right)^{2}\right) ; & \left.\frac{d Q}{d V}\right|_{\omega=c}=0 \\
\left.\frac{d P}{d \omega}\right|_{V=c}=-\frac{Q_{0}^{2}}{\omega P} ; & \left.\frac{d Q}{d \omega}\right|_{V=c}=\frac{Q_{0}}{\omega}
\end{array}
$$

\subsection{Induction Motor Load Models}

5.4.1 A Combined static/Dynamic Representation of Lnduction Machines

Induction motor representation can be a compromise between accuracy 
and simplicity. For transient stability studies where linearization of models is not possible, even a simplified model of the induction machine that would nevertheless account for rotor electrical transients appears to be already too complex. This is why the model opted for here does not explicitly take into account any electrical transients, and consists essentially of steady state electrical equations coupled with mechanical equations.

(i) Electrical equations:

A simplified equivalent circuit of an induction machine is shown in Fig. 5.1. on the basis of this circuit, active and reactive power of loads are given by:

$$
\begin{gathered}
P-4 \frac{V^{2}}{X} \frac{s / s c r}{1+(s / s c r)^{2}} \\
Q=q \frac{v^{<}}{X} \frac{X / X_{m}+(s / s c r)^{2}\left(1+x / X_{m}\right)}{1+(s / s c r)^{2}}
\end{gathered}
$$

where $\operatorname{scr}=R_{2} / X$ and $q$ is the number of phases.

\section{(ii) Slip equation:}

Rotor shaft dyna mics are described by:

$$
T_{e}=\ddot{T}_{s}+t_{f}+t_{J}
$$

where

$$
\begin{aligned}
& T_{e}=\text { electrical torque } \\
& T_{s}=\text { shaft torque } \\
& T_{J}=\text { inertia torque } \\
& T_{f}=\text { frictional torque }
\end{aligned}
$$




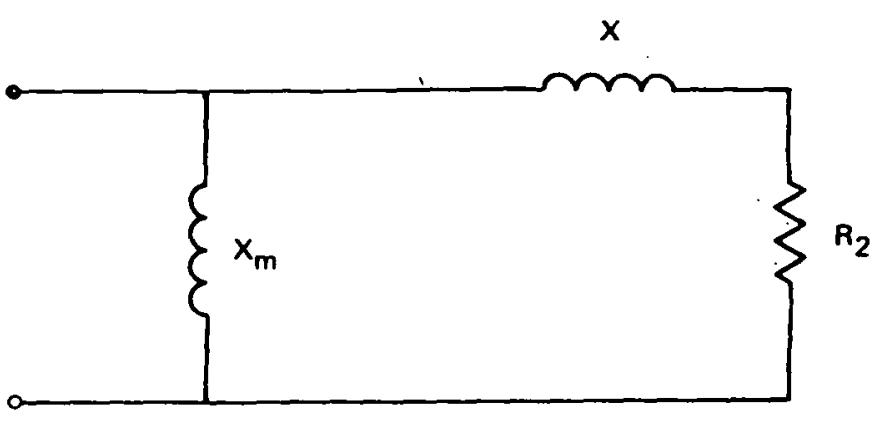

Figure 5.1 Simplified induction motor equivalent circuit.

(a)

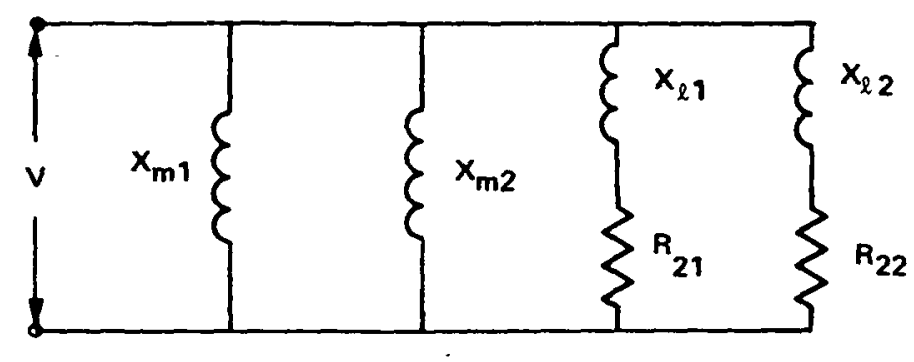

(b)

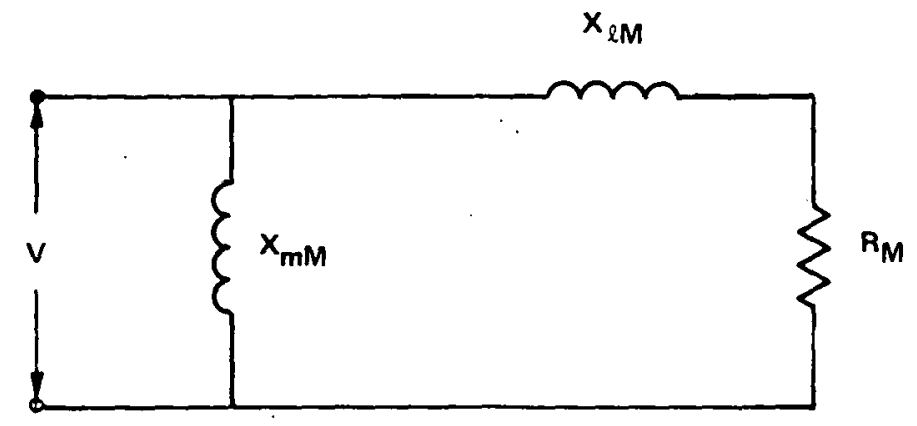

Figure 5.2 Simplified equivalent circuit representing two motors in paraltel. (a) original circuit (b) reduced circuit.

From Abdel Makim and Berg (1976) 
The electrical torque can be expressed as:

$$
T_{e}=\frac{P_{\text {mech }}}{\omega_{R}}=\frac{g V^{2} s / s c r}{X \omega_{s}\left(1+(s / s c r)^{2}\right)}
$$

where, ${ }^{\omega}{ }_{\mathbf{r}}, \omega_{\mathbf{s}}$ stand for rotor actual and synchronous speeds respectively. Also:

$$
T_{f} \approx B \omega_{s}(1-s)
$$

where $B$ is the shaft ccefficient of friction and:

$$
\mathrm{T}_{\mathrm{J}}=-\mathrm{J} \cdot \mathrm{s} \omega_{\mathrm{s}}
$$

where, $\mathrm{J}$ represents the angular a mount of inertia of the machine. Furthermore, if the torque speed characteristic of the induction motor is approxim ated by:

$$
T_{s}\left(\omega_{R}\right)=k \omega_{R}^{B}=k\left(\left(1-s^{\prime} \omega_{s}\right) \beta\right.
$$

then substitution of $(5.4 .4)-(5.4 .6)$ in $(5.4 .3)$ yields:

$$
\frac{q V^{2}(s / s c r)^{2}}{X \omega_{s}\left(1+(s / s c r)^{2}\right)}=K\left((1-s) \omega_{s}\right)^{\beta}+B \omega_{s}(1-s)-\dot{s} J \omega_{s}
$$

Consequently, the electromechanical behavior of the induction machine can be studied by solving equations (5.4.8) for the instantaneous slip and substituting the results in equations $(5.4: 1-2)$ to obtain active and reartive fower flows in thi m achine.

\subsubsection{A Linearized Model for the Induction Machine}

If interest is confined to the areas of $\mathrm{small}$ signal stability or automatic generation control, a more detailed model of the induction 
machine can be used, since linearization of the model is possible in this case, thereby simplifying somewhat the tasik of aggregating the $m$ achines. Equations for a linear model of the induction machine where only stator electrical transients and saturation : effects are neglected were developed in Ref. (30) and are reported here for convenient reference. - .

\section{State equations}

$$
\frac{d}{d t}\left[\begin{array}{c}
\Delta i_{d} \\
\Delta i_{r d} \\
\Delta i_{q} \\
\Delta i_{r q} \\
\Delta n_{r}
\end{array}\right]=-[X]^{-1}[A]\left[\begin{array}{c}
\Delta i_{d} \\
\Delta i_{r d} \\
\Delta i_{q} \\
\Delta i_{r q} \\
\Delta n_{r}
\end{array}\right]
$$

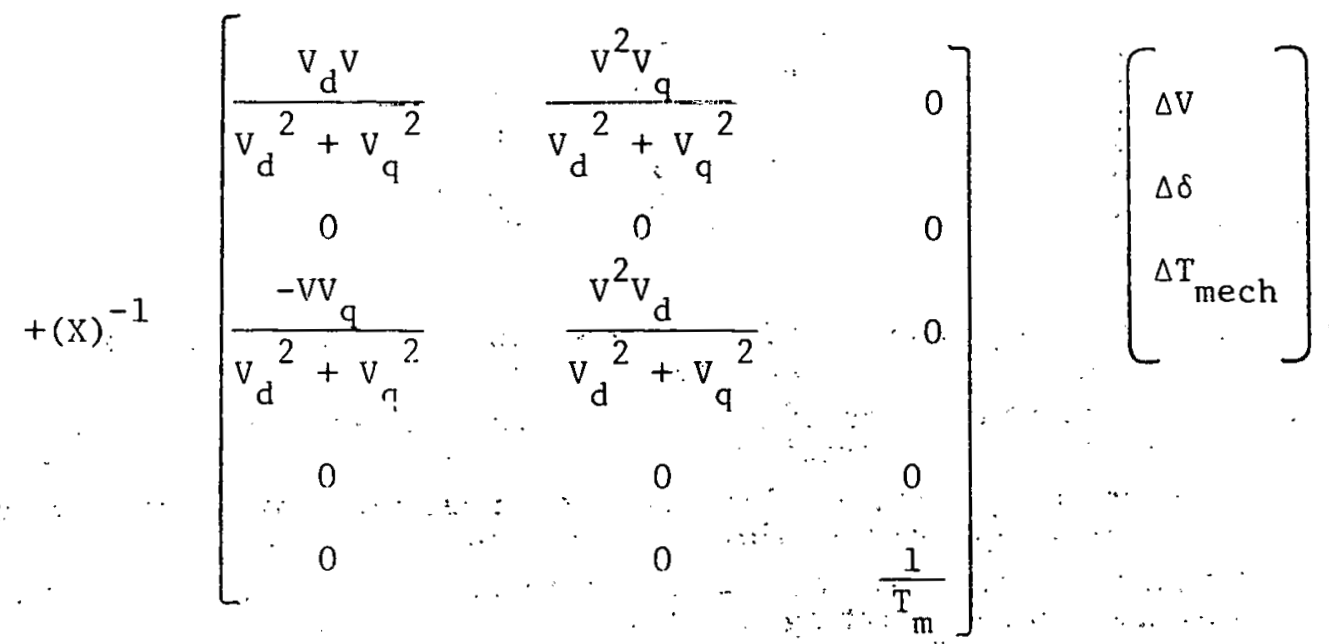

\section{Output equations}

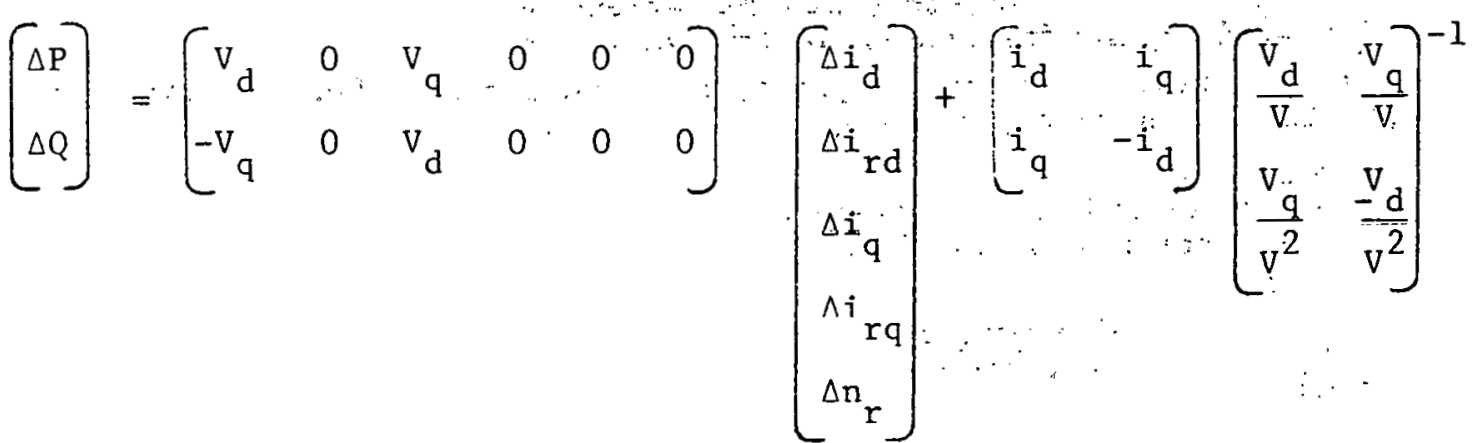


where

$$
\begin{aligned}
& \because \therefore]=\left[\begin{array}{lllll}
R_{s} & 0 & -x_{s} & -x_{m} & 0 \\
0 & R_{r} & -s x_{m} & -s x_{r} & -x_{r q} \\
0 & 0 & R_{s} & 0 & 0 \\
-s X_{m} & -s X_{r} & 0 & 0 & x_{r d} \\
\frac{i_{q} x_{s}-x_{q}}{T_{m}} & i_{q} x_{m} & \frac{x_{d}-i_{d} x_{s}}{T_{m}} & \frac{-i_{d} x_{m}}{T_{m}} & 0
\end{array}\right] \\
& {[\mathrm{X}]=\left[\begin{array}{ccccc}
\frac{\mathrm{x}_{\mathrm{s}}}{\omega_{0}} & \frac{\mathrm{x}_{\mathrm{m}}}{\omega_{0}} & 0 & 0 & 0 \\
\frac{\mathrm{x}_{\mathrm{m}}}{\omega_{0}} & \frac{\mathrm{x}_{\mathrm{r}}}{\omega_{0}} & 0 & 0 & 0 \\
0 & 0 & \frac{\mathrm{x}_{\mathrm{s}}}{\omega_{0}} & \frac{\mathrm{x}_{\mathrm{m}}}{\omega_{0}} & 0 \\
0 & 0 & \frac{\mathrm{x}_{\mathrm{m}}}{\omega_{0}} & \frac{\mathrm{x}_{\mathrm{r}}}{\omega_{0}} & 0 \\
0 & 0 & 0 & 0 & 1
\end{array}\right]}
\end{aligned}
$$

In the above equations, all voltages and currents are direct and quadnature axis quantities obtained from corresponding stator and rotor voltage and current quantities through the classical Park transformation with a reference frame rotating at synchronous speed. Furthermore, the following notstion is used (25):

$$
\begin{aligned}
& \omega_{0}=\text { rated angular frequency, electric radians/sec } \\
& \omega_{r}=\text { instantaneous angular frequency of machine rotor, electric radians/sec. } \\
& n_{r}=\frac{\omega_{r}}{\omega_{0}}=\text { per unit angular frequency } \\
& T_{m \text { ech }}=\text { m echanical torque } \\
& T_{m}=2 H=\text { inertia time constant, seconds }
\end{aligned}
$$




\subsubsection{Aggregation Probliems}

\section{a. Large Induction Machines}

In the following, the problem of aggregation of large induction $m$ achines will be considered. Simulation results reported by niceto and capasso ${ }^{(28)}$ seem to establish that for "large" induction motors, direct aggregation is possible and predicts reașonably well power fluctuations under disturbances of various kinds. An experimentally obtained criterion allows the selection of induction machines that should be included in this group, and can be written as follows ${ }^{(23)}$ :

$$
H>\frac{1}{2} T^{-} \text {do }
$$

where:

$\mathrm{H}=$ constant of inertia (motor and driven m achines), seconds.

$\mathrm{T}^{\prime}{ }_{\mathrm{do}}=$ time constant of rotor with open-circuited stator (calculated for rated value of slip), seconds.

In other words, all the machines satisfying the above condition can be successfully represented by. one equivalent m achine:

On the other hand, an interesting aggregation methodology has been proposed by Abdel Hakim and Berg ${ }^{(29)}$. Aggregation proceeds by considering a pair of $m$ achines at a time, and computing para meters of an equivalent machine.

Figure 5.2(a) describes the equivalent circuits of two induction machines at standstill, whereas Fig. 5.2(b) describes the circuit of the equivalent $m$ achines if che following constraints are to be satisfied:

(i) active and reactive power invariance at standstill

(ii) active and reactive power invariance at nominal conditions

(iii) conservation of rotational kinetic energy at synchronous speed

Moreover, if torque-speed characteristics are assumed to be of exponential form $T_{e}(\omega)=T_{0} \omega^{\beta}$ (as in Section 5.4.1), and invariance of total mechanical input power at synchronous speed, and nominal speeds, the following results can be derived ${ }^{(29)}$ : 


$$
\begin{aligned}
X_{M} & =\frac{x_{m 1}-x_{m 2}}{x_{m 1}+x_{m 2}} \\
R_{M} & =\frac{R_{21}\left(x_{\ell 2}^{2}+R_{22}^{2}\right)+R_{22}\left(x_{\ell 1}^{2}+R_{21}^{2}\right)}{\left(R_{21}+R_{22}\right)^{2}+\left(x_{\ell 1}+x_{\ell 2}\right)^{2}}
\end{aligned}
$$

and

$$
x_{\ell M}=\frac{x_{\ell 1}\left(x_{\ell 2}^{2}+R_{22}^{2}\right)+x_{\ell 2}\left(x_{\ell 1}^{2}+R_{21}^{2}\right)}{\left(R_{21}+R_{22}\right)^{2}+\left(x_{\ell 1}+x_{\ell 2}\right)^{2}}
$$

The equivalent slip $s_{M}$ is given by:

$$
\begin{aligned}
& s_{M}=\frac{\left[k_{21}\left(x_{\ell 2}^{2}+k_{22}^{2}\right)+k_{22}\left(x_{\ell 1}^{2}+k_{21}^{2}\right)\right]\left[\left(k_{21}^{1}+k_{22}^{1}\right)^{2}+\left(x_{\ell 1}+x_{\ell 2}\right)^{2}\right]}{\left[k_{21}^{1}\left(x_{\ell 2}^{2}+k_{22}^{12}\right)+R_{22}^{1}\left(x_{\ell 1}^{2} w R_{21}^{12}\right)\right]\left[\left(R_{21}+R_{22}\right)^{2}+\left(x_{\ell 1}+x_{\ell 2}\right)^{2}\right]} \\
& \text { where } R_{21}^{1}=\frac{R_{21}}{s_{l}} \text { and } R_{22}^{1}=\frac{R_{22}}{s_{2}}
\end{aligned}
$$

and $s_{1}$ and $s_{2}$ are nominal slips of machines 1 and 2 .

The equivalent inertia constant is given by:

$H_{M}=\frac{M_{1}(V A)_{1}+M_{2}(V A)_{2}}{(V \Lambda)_{1}+(V \Lambda)_{2}}$

wherein $(V A)_{1},(V A)_{2}$ are the VA ratings of the machines.

Finally, the combined torque-speed characteristic is given by:

$$
\mathrm{T}_{P_{\mathrm{m}}}=\mathrm{T}_{\mathrm{nm}} \omega_{\mathrm{n}} \hat{s}_{\mathrm{M}}
$$

where

$$
\mathrm{T}_{\text {on }}=\mathrm{T}_{01}+\mathrm{T}_{02}
$$

and:

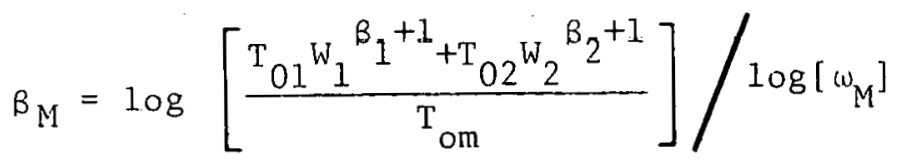


The above approach will be followed for the aggregation of large induction machines. Note that this implies that the given power utility has a complete knowledge of parameters and schedule of large induction m achines connected to the network.

b. Medium and $\mathrm{S} m$ all $\mathrm{R}$ ating Induction Machines

For medium and small rating induction mähines $\left(H<\frac{1}{2} \mathrm{~T}^{-}\right.$do $)$, at best, incomplete knowledge of the load is available. Here, randomization of the analysis is necessary ${ }^{(28)}$, not only because of the fuzzy knowledge of this portion of the load, but also because the loading factor of the motor varies randomly from 0 to $100 \%$. Also, it appears from simulation results reported in $R$ ef. (28) that a single unit representation of this portion of the load, even if complete knowledge of the parameters is assum ed, is inadequate.

However, and this is an assumption that should be verified against simulation results, it would seem that for that class of loads, mechanical transients are negligible. Aggregation could then proceed in the following three steps:

(i) Gather statistical information for the distribution of relevant param eters as a function of power ratings within this class

(ii) Utilize a pattern recognition ty.pe of approach to determine the subclasses of motors that display similarity in their response curves

(iii) Use the information in (i) to aggregate equations (5.4.1-2) for each subclass. Here, it is important to note that the aggregation is somewhat simplified due to the fact that equation $(5.4 .2 .8)$ can be made algebraic by assuming mechanical steady state. An "expected" normalized aggregate response curve would then be obtained for each subclass of m otors. 
Even: if the above aggregation 'methodology succeeds; therer still' remains the problem of determining on the average how many motors are "ON" in each power class at every time of the day. In other words, a "functional model" has to be associated with each power class. The output of this functional model is a stochastic process that would modulate in time the response curve of the power class it is associated with.

Obtaining the above functional model is a difficult task, since it is partly associated with the problem of building load modeling; and will be given considerable attention in the future. 

$-1$.
APPENDIX A

FUNCTIUNAL MODEL FOR ELECTRIC WATER HEATER

In this appendix, we consider a simplified model of a single element electric water heater. A complete model will involve more differential equations but our model is sufficient for the intended use in this study.

Let the following quantities be defined:

$v(t): \quad$ hot water demand at time $t$ (vol./sec.) 、

$x_{i}(t): \quad$ inlet water temperature

C: tank thermal capacity

$x(t): \quad$ tank water temperature at time $t$

$x_{d}$ : desired water outlet temperature

$v_{h}(t)$ : hot water removed at temperature $x(t)$ (vol./sec.)

$v_{c}(t)$ : cold water mixed with $v_{d}(t)$ (vol./sec.)

$\alpha$ : heat loss constant

$x_{a}(t):$ ambient temperature

$p(t)$ : $\quad$ power supplied by the heater element

$m(t)$ : functional state of the heater

From volume balance, we have

$v(t)=v_{h}(t)+v_{c}(t)$

From heat balance, for small $t$, we have

$C x(t+\Delta t)=C x(t)-\alpha\left(x(t)-x_{a}(t)\right) \Delta t-v_{h}(t)\left(x(t)-x_{i}(t)\right) \Delta t$

$+p(t) m(t) \Delta t$

(A.2) 


$$
\begin{aligned}
C(x(t+\Delta t)-x(t))= & -x\left(x(t)-x_{a}(t)\right) \Delta t-v_{h}(t)\left(x(t)-x_{i}(t)\right) \Delta t \\
& +y(t) m(t) \Delta t
\end{aligned}
$$

Dividing by $\Delta t$ and letting $\Delta t$ approach 0 , we obtain

$$
\begin{aligned}
C \frac{\mathrm{dx}(t)}{\mathrm{dt}}= & -\alpha\left(x(t)-x_{a}(t)\right)-v_{\mathrm{h}}(t)\left(x(t)-\mathrm{x}_{i}(t)\right) \\
& +y(t) m(t)
\end{aligned}
$$

But

$$
v_{h} \ddot{(t} \dot{j}_{x}(L)+v_{c}(L) x_{j}(c)=v(c) \dot{x}_{d}
$$

and

$$
v_{h}(t) x_{i}(t)+v_{c}(t) x_{i}(t)=v(t) x_{i}(t)
$$

Thus

$$
v_{i 1}(t)\left(x(t)-x_{i}(t)\right)=v(t)\left(x_{d}-x_{i}(t)\right)
$$

Substituting into equation ( A.3), the pquation becomes

$$
C \frac{d x(t)}{d t}=-u\left(x(t)-x_{a}(t)\right)-v(t)\left(x_{d}-x_{i}(t)\right)+p(t)_{m}(t)
$$


APPENDIX $B$

FUNCTIUNAL/ELECTRICAL MODELS OF BUILDINGS

\section{B.l Introduction}

The bulk of electrical consumption takes place in buildings, especially if we set aside industrial loads which have their own characteristics. Depending on the type of building (residential, office, educational, etc.), there are a variety of demand use patterns that can be identified. For example, in residential buildings, one can identify types of electrical devices used together with the statistics of their utilization. This holus true for office buildings, as well as others.

A major component of electrical load in a good fraction of buildings is due to space conditioning, i.e., heating and cooling. In a majority of utility systems, air conditioning accounts for a substantial fraction of the load in the sumner. Normally the weather-sensitive component of the load accounts for peak electrical demand, causing operational, planning and economic problems.

Heating and cooling of buildings is performed using a variety of electrical devices such as

- Dascouard resistive heaters

- heat pumps

- compressisr-type chillers

- Eans

Even in solar space-conditioning systems electrical devices are used, such as puinps, auxiliary heaters, as well as fans. 
In this appendix we shall outline the concepts associated with the development of a functional/electrical load model for buildings.

\section{B.2 Structure of a Building Load Model}

State-of-the-art simulation models ${ }^{(31)}$ for computing hourly performance of buildings are based on a minimum of two basic steps. In the first step the assumption is made that the interior of the building is maintained at constant, but specified, temperature. In other words, the assumption is made that the space conditioning equipment and associated control syste $m$ is capable of $m$ aintaining required comfort conditions inside the building. We shall refer to this step as the Load Requirements Block ( $L R B$ ). Inputs to LRB consist of weather data (dry and wet bulb temperatures, wind speed, solar radiation, and cloud covers) and schedules of energy generating syste ms wathin the building (like occupancy, use patterns of appliances, and the like). The outputs of L R B consist of hourly energy : gains or losses for each zone in the building.

These LRB outputs are taken as inputs to the second simulation step which we shall refer to as the $\mathrm{Com}$ fort Control Block ( $\mathrm{C} \mathrm{CB}$ ). In this block, perturbation (linear) models are used to calculate on-off switching requirements for electrical devices, as well as outside air inputs as required to reduce energy demands. In large buildings, the compressor-chillers are modulated in tineir outputs as proportional devices rather than purely on-off devices

\section{B.3 Mathe matcal Model Description}

In general, linear syste $m$ analysis is utilized in most. model blocks dcscribing the LRB and $\mathrm{CCB}$ blocks. Although the physics of the problem suggests nonlinear thermal characteristics, approximately linear behavior 


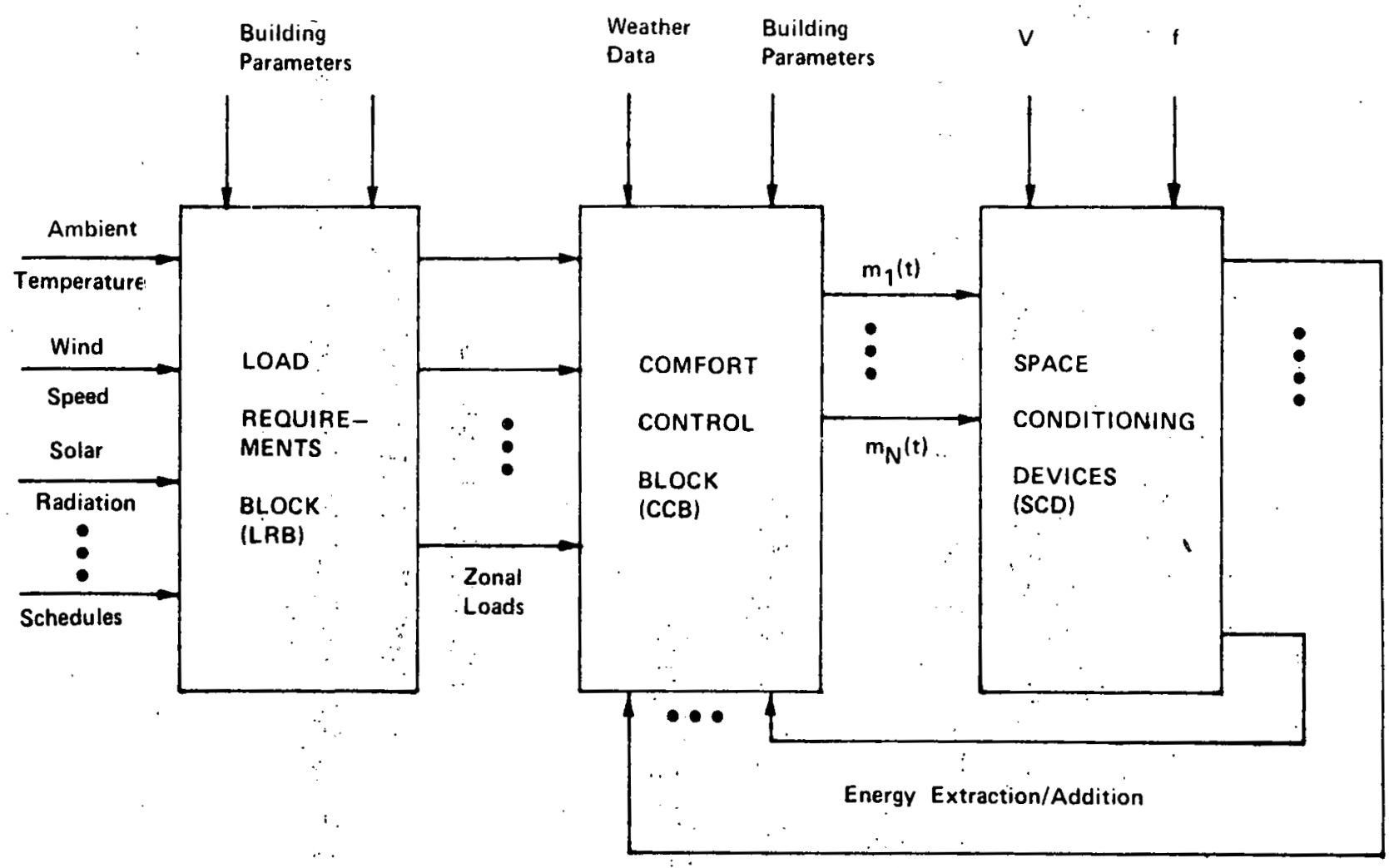

Figure B.1 Structure of a Building Load Simulation Model 
has been proposed and verified. As a result, tine most advanced simoliation programs (DOE-1, NBSLD, etc.) utilize linear models.

In the LRB block, a set of transfer functions (referred to as response factors) are associated with each wall sectinn. These response facturs describe the dynamics of heat transfer characteristics, given temperature and solar radiation inputs. Another set of transier functions (so called veighting factors) describe the dynamics of heat transfer froti interior wall surfaces to the rooms (floors, ceilings, furniture, etc.) Since rooms are maintained (by assumption) at constant temperatures, inter-zonal heat. trangfer is zero. Thus, in abstrace form, the dynamics of the i.k 3 block arc given by

$$
\begin{aligned}
& x_{1}=A_{11} x_{1}+A_{12} x_{20}+F_{1}(t) \\
& y_{1}=C_{1} x_{1}+F_{1} f_{1}(t)
\end{aligned}
$$

where

$$
\begin{array}{ll}
x_{1} & =\text { state vector of LR B clock } \\
x_{20} & =\text { vector of zonal te meratures } \\
f_{1}(t)=\text { vector of rando m inputs (weather, schetules, etc.) } & \\
y_{1} & =\text { vector of zonal loads }
\end{array}
$$

In the C C B block, the main concern is to meet the dem ants $y_{1}(t)$ as clnstly as possible. The dynamics are given by:

$$
\dot{x}_{2}=A_{22} x_{2}+B_{21} y_{1}(t)+B_{22}{ }^{\prime}(t)
$$

where $x_{2}$ is the deviation of zonal temperatures from set-point temperatures $x_{20}$. The in atrix $A_{22}$ will account for inter-zonal heat transfers. The control input u(t.) is composed of two basic components: (a) Outride 
- air inputs and (b) Electrical devioge inputs.

The above simplified version of the building model can serve to i.llustrate the required functional/electrical decomposition. 
1. Witsenhausen, H.S., "A Class of Hybrid-State Continuous-Time Dynamic Systems," IEEE Transactions on Automatic Control, vol. AC-11, no. 2, pp. 161-167, Apri1 1966.

2. Cox, D. R. and Miller, H. D., The Theory of Stochastic Processes, Wiley, New York 1965.

3. Woodard, J. B., "Electrical Load Modeling," Ph.D. Thesis, M.I.T., 1974 .

4. Andre, J. and Siebert, P., "After End-point Motions of General Discontinuous Control Systems and Their Stability Properties," Proceedings of First IFAC Congress, Moscow, 1960, pp. 819-922.

5. Utkin, V. I., "Variable Structure System with Sliding Modes," IEEE Trans. on Autom. Contr., vol. AC-22, no. 2, pp. 212-222, April $\overline{1977}$.

6. Filippov; A. G:; "Application of the Thcory of Diffcrential Equationo with Discontinuous Right-hand Sides to Non-Linear Problems in Automatic Control," Procoodinge of Firet IFAC Congreec, Moecow, 1960, Pp. 923-927.

7. Aizerman, M. A. and Pyatnitskii, E. S., "Foundations of a Theory of Discontinuous Systems,. I, II," Automation and Remote Control, pP. 1066-1079, 1242-1262, 1974.

8. Flugge-Lotz, I., Discontinuous Automatic Control, Princeton University Press, $195 \overline{3}$.

9. Johnson, T. L., "Finite-State Compensators for Continuous Systems," Proceedings of Seventh IFAC Congress, PP. 1823-1831, 1978.

10. Snyder, D. L., Random Point Processes, Wiley, 1975.

11. Davis, M. H. A., "The Representation of Martingales of Jump Processes," SIAM J. Cont. and Opt., vol. 14, no. 4, pp. 623-638, July 1976.

12. Varaiya, P. P., "The Martingale Theory of Jump Processes, IEEE Trans. Automatic Contr., vol. AC-20, no. 1, Pp. 34-42, Feb. 1975 .

13. Boel, R., Varaiya P., and Wong, $\bar{E}$., "Martingales on Jump Processes, I: Representation Results, and II: Applications," SIAM J. Control, vol. 13, no. 5, pp. 999-1061, Aug. 1975.

14. Marcus, S. I., "Modeling and Analysis of Stochastic Differential Equations Driven by Point Processes," IEEE Trans. on Information Theory, vol. IT-24, no. 2, Pp. 164-172, March 1978 . 
- 15 . Wonham, W. M., "Random Differential Equations in Control Theory," in Probabilistic Methods in Applied Math, Vol. 2, Academic, New York, 1970 .

16. Bharucha-Reid, A. T., Elements of the Theory of Markov Processes and Their Applications, Mc Graw-Hill, New York, 1960.

17. Darling, D. A., and Siegert, A. J. F., "The First Passage Time Problem For a Continuous Markov Process," Annal of Math. Stat., vol. 24, pp. $624-639,1953$.

18. Gusak, D. V. and Koralyak, "On the First Passage Time Across a Given Level for Processes with Independent Increments," Theory of Probability and its Applications, vol. 13, no. 1, pp. 448-456, 1968 .

19. Cinlar, E., "Superposition of Point Processes," in Stochastic Point Processes Statistical Analysis, Theory, and Applications, Ed. P. A. W. Lewis, Wiley, New York, 1972 .

20. Grigelionis, B., "On Weak Convergence of the Sums of Multivariate Stochastic Point Processes," in Stochastic Point Processes Statistical Analysis, Theory, and Applications, Ed. P. A. W. Lewis, Wiley, New York, 1972.

21. Rau, N. S. and Graham, R. W., "Analysis and Simulation of the Effects of Controlled Water Heaters in a Winter Peaking System," IEEE Transactions on Power Apparatus and Systems, vol. PAS-98, no. 2, pp. 458-464, March/Apri1 1979.

22. Chen, Mo-Shing, "Determining Load Characteristics for Transient Performances," Energy System Research Center Report, University of Texas at Arlington, 1978.

23. Berg, G. R. and Kar, A. K., "Model Representation of Power System Loads," PICA Conference Proceedings, PP. 153-162, 1971.

24. Akhtar, M. Y, "Frequency-Dependent Power System Static-Load Characteristics," Proceedings of the IEE, vol. 115, pp. 1307-1314, 1968.

25. Kar, A. K, "Load Behavior and Representation in Electrical Power Systems," MSC Thesis, Department of Electrical Engineering, The University of Calgary, 1970.

26. Ravenscroft, J., "The Determination of the Electrical Characteristics of an ARC Furnace," PROC. IEE, vol. 108A, pp. 140-148, 1961.

27. Iliceto, F., Ceyhan, A., and Ruckstuhl, G., "Behavior of Loads During Voltage Dips Encountered in Stability Studies--Field and Laboratory Tests," IEEE proper T72169-6.

28. Iliceto, F. and Capasso, A., "Dynamic Equivalents of Asynchronous Motor Loads in System Stability Studies," IEEE Trans. Power App.

Syst., vol. PAS-93, pp. 1650-1659, 1974. 
29. Abdel-Hakim, M. M. and Berg, G. J.," "Dynamic" Single-ünit Representation of Induction Motor Groups," IEEE Trans. Power App. Syst., ỳol. PAS-95, pp. 155-165, January/Februáry 1976.

30. Mauricio, $W$ and Semlyen, A., "Effect of Load Characteristics on the Dynamic Stability of Power Syste ms," IE EE paper T 72 019-3.

31. Lokmanhekim M. et al, "DOE-1 (Formerly Cal-ER DA), A New State of the Árt Computer program for the Energy Utilization Analysis of Buildings," Paper presented at the Third International Symposium on the Use of Computers for Environmental Engineering Related to Buildings, held in Banff, Alberta, Canada, May 10-12, 1978. 